\title{
LA RETE ECCLESIASTICA IN TOSCANA SETTENTRIONALE (IV-X SECOLO). DATI E RIFLESSIONI ALLA LUCE DEL PROGETTO CARE
}

\author{
GABRIELE CASTIGLIA
}

UDC: $27-523(450.52) " 03 / 09 "$

Preliminary communication

Manuscript received: 10. 11. 2016.

Revised manuscript accepted: 14. 02. 2017.

DOI: 10.1484/J.HAM.5.113759
G. Castiglia
Pontificio Istituto di Archeologia Cristiana
Roma
Italia

The aim of this paper is to present a general overview of the formation and diffusion of the ecclesiastical network, both urban and rural, in the territory corresponding to the actual boundaries of Northern Tuscany, from the 4th century A.D. to the 10th. The research is based on the CARE project (directed by M. Jurkovic and G.P. Brogiolo), in which the author is studying and recording all the churches for such area. The diffusion of a topography of the christian buildings starts from the late 4th-early 5th century in the major towns, such as Lucca and Firenze where, by the end of the Gth, is fully spread, comprehending also important funerary buildings in the suburbia; in the rural areas, instead, the diffusion of the churches in the Late Antique centuries seems to be weaker, even though significant buildings are well known, like San Piero a Grado and others, signs of a progressive christianization of the countrysides, which will reach its heyday from the Lombard era onwards and, even more, in the Carolingian period.

Keywords: Tuscia Annonaria, Tuscia Langobardorum (Northern Tuscany), Late Antiquity, Early Middle Ages, Christian Topography, Rural church networks, Episcopal complexes, Urban evolutions

\section{THE ELEPHANT IN THE SITTING ROOM: LE RAGIONI DI UN PROGETTO E DI UN DIBATTITO DA RILANCIARE}

Nel 2007, Ian Wood, proponendo alcune considerazioni generali sull'alto medioevo europeo, affermò che "in downplaying the institution of the church, as opposed to religion, we fail to recognize the elephant in the sitting room" ${ }^{1}$. Poco tempo dopo, Richard Hodges riprese questa definizione, applicandola in particolare al contesto toscano, affermando, però, come "l'elefante si era innegabilmente perso nel salotto e, come queste indagini archeologiche così elegantemente eseguite dimostrano, il posto della chiesa per ragioni storiche e storiografiche è stato ingrandito" ${ }^{2}$. E proprio partendo da questi due punti di vista, in parte divergenti, che nasce l'idea di questo contributo, con l'intento di proporre un aggiornamento di sintesi sui dati a disposizione per quanto concerne gli edifici ecclesiastici (urbani e rurali) dal IV al X secolo nel territorio corrispondente a buona parte dell'attuale Toscana settentrionale: chi scrive, infatti, si occupa da alcuni anni della schedatura di siffatte emergenze per le province di Lucca, Pistoia, Prato e Firenze, nell'ambito del progetto $C A R E^{3}$ (fig. 1).

Da un punto di vista squisitamente metodologico, dunque, la ricerca è stata impostata innanzitutto sulla creazione di una banca dati, ove sono confluite le informazioni ricavabili dalla sistematica analisi e revisione dell'edito, inerenti sia i contesti indagati archeologicamente che quelli noti esclusivamente dalle attestazioni presenti nelle fonti scritte, integrate, ove possibile, dagli elementi emersi durante sopralluoghi fisici effettuati direttamente da chi scrive ${ }^{4}$. Le istanze di questo studio, dunque, da un lato muovono dalla connaturata esigenza di proporre un aggiornamento sullo stato dell'arte del CARE in parte del territorio toscano 5 e, dall'altro, dall'urgenza di rinnovare un dibattito - quello dell'incidenza della cristianizzazione e successiva strutturazione della rete ecclesiastica nella Tuscia tardo antica ed alto medievale, in primis in relazione alle morfogensi insediative e politiche che qui occorsero nell'ampio lasso di tempo compreso tra il IV ed il X secolo - a lungo sopito e tenuto in disparte, soprattutto rispetto ad altre tematiche e

\footnotetext{
${ }^{1}$ I. WOOD, Review article: Landscapes compared, in Early Medieval Europe, 15, 2007, p. 223-237.

${ }^{2}$ R. HODGES, L'elefante nel salotto, in S. Campana, C. Felici, R. Francovich, F. Gabbrielli (a cura di), Chiese e insediamenti nei secoli di formazione dei paesaggi medievali della Toscana (V-X secolo), Atti del seminario (San Giovanni d'Asso-Montisi, 10-11 novembre 2006), Firenze, 2008, p. 436-443.

${ }^{3}$ I responsabili del progetto CARE sono Miljenko Jurkovic e Gian Pietro Brogiolo (si veda anche la nota 5 per la bibliografia specifica), mentre il coordinamento per la regione Toscana è affidato a Marco Valenti, sotto la cui guida il sottoscritto svolge la propria attività di schedatura, nell'ambito di una più ampia ricerca storico-topografica (comprensiva anche dell'areale pisano), seguita da Philippe Pergola e finanziata dal Pontificio Istituto di Archeologia Cristiana di Roma nell'ambito del Dottorato di Ricerca. L'autore desidera ringraziare sentitamente Alexandra Chavarría Arnau per aver attentamente letto il manoscritto e per le sue preziose osservazioni e suggerimenti; un grande ringraziamento va anche a Federico Guidobaldi, per la sua costante disponibilità. ${ }^{4}$ Allo stato attuale sono stati schedati 223 edifici ecclesiastici, archiviati sia in formato cartaceo, con schede dettagliate, sia in un database digitale, sia, in parte, nel sito ufficiale del progetto CARE Italia in una piattaforma wiki consultabile on-line (http://arcmed.lettere.unipd.it/care/index.php/Pagina_principale): in questa ricerca, però, vengono considerati anche alcuni contesti posti alcuni $\mathrm{km}$ al di fuori del territorio di diretta pertinenza del sottoscritto, ritenuti fondamentali nell'espletamento del ragionamento storico-topografico che qui si vuole proporre.

${ }_{5}^{5}$ Sul progetto C.A.R.E. in generale si rimanda al numero monografico di Hortus Artium Medievalium del 2012, ad esso dedicato, con aggiornamenti sia prettamente metodologici che dedicati a singole aree e regioni: in particolare si veda G.P. BROGIOLO, M. JURKOVIĆ, Corpus Architecturae Religiosae Europeae (IV-X saec.). Introduction, in Hortus Artium Medievalium, 18, 2012, p. 7-26; inoltre, per un primo volume edito si veda G.P. BROGIOLO, M. IBSEN, M. JURKOVIĆ, Corpus Architecturae Religiosae Europeae (IV-X saec.), 2.1 Italia. Province di Belluno, Treviso, Padova, Vicenza, Zagreb, 2009.
} 


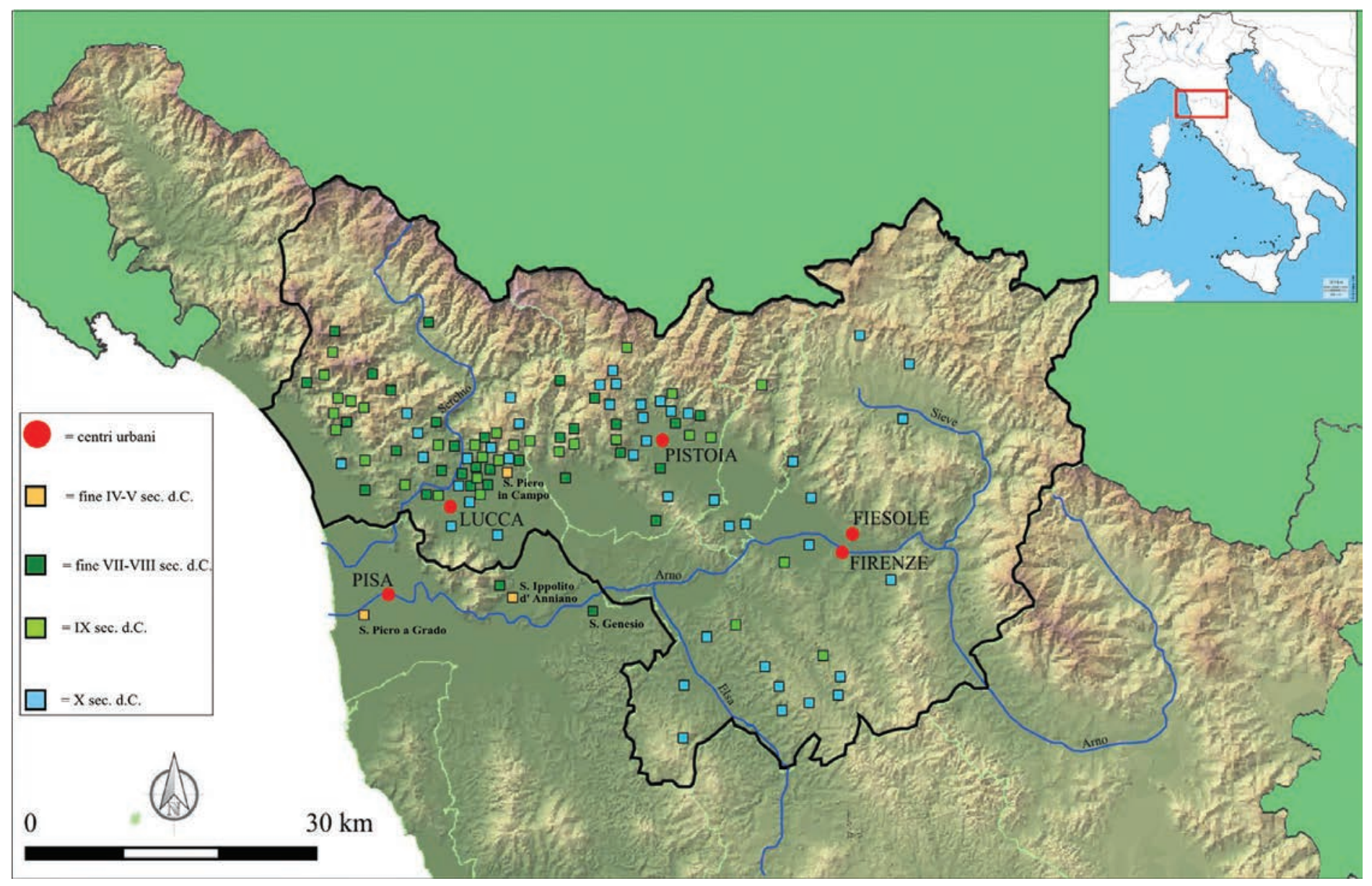

Fig. 1: Cartografia con i principali edifici schedati e menzionati nel testo, suddivisi per ambiti cronologici; in nero sono evidenziati i limiti territoriali della zona di schedatura (elaboraz. a.).

linee di ricerca che per decenni hanno svolto un ruolo centrale nella 'scuola' toscana. Non sembra essere un caso che, infatti, ancora nel 2004, Riccardo Francovich affermasse che "in Toscana le conoscenze sulle chiese rurali tardo antiche e alto medievali sono scarse, soprattutto nei loro rapporti con i quadri insediativi"': solo in tempi relativamente recenti, grazie a ricerche programmatiche in determinati 'siti chiave', l'interesse per lo studio e l'approfondimento di un tema centrale quale l'inecclesiamento'7 delle aree rurali ha ripreso piede ${ }^{8}$ mentre, come vedremo, nelle città (soprattutto Lucca e Firenze) lo stato delle conoscenze si attesti a livelli più avanzati, sebbene anche in tale ambito le potenzialità inespresse siano ancora numerose.

Ancora oggi, il punto di riferimento imprescindibile nella ricerca rimane il per certi versi insuperato contributo di Cinzio Violante alla settimana spoletina del $1980^{9}$, in cui il celebre storico offriva un panorama amplissimo sulla formazione delle strutture della cura animarum in Italia centro-settentrionale, basandosi quasi esclusivamente sulle fonti scritte $^{10}$ : per quanto attiene i secoli tardo antichi, Cinzio Violante proponeva, per il territorio toscano, un quadro che si potrebbe definire a tratti desolante, caratterizzato da una incisiva e quasi irreversibile contrazione insediativa, in cui le "fondazioni ecclesiastiche" erano "scarse, insicure" lando il proprio modello su una lettera di papa Gelasio (diretta al vescovo Palladio) che, invero, sembrerebbe necessitare di una parziale revisione critica. Nel frammento epistolare, infatti, il pontefice affermava che Sed nupe, propter provinciae vastitatem, quam Tusciae prae omnibus barbarorum diversa sectantium et ambiguitas invexit animorum, quum

${ }^{6}$ R. FRANCOVICH, Villaggi dell'altomedioevo: invisibilità sociale e labilità archeologica, in M. VALENTI, L'insediamento altomedievale nelle campagne toscane. Paesaggi, popolamento e villaggi tra VI e X secolo, Firenze, 2004, p. IX-XXII. Posizioni affini, alcuni anni dopo, venivano espresse anche da Gian Pietro Brogiolo, che sempre in relazione alla Toscana affermava che "appare sempre più evidente che un modello valido per un territorio non può essere costruito a partire dallo scavo di un solo tipo di insediamento" e, ancora, che "in questa ricostruzione dei paesaggi altomedievali, i luoghi di culto occupano una posizione importante, purché non vegano studiati isolatamente, ma in rapporto all'insediamento" (G.P. BROGIOLO, Tavola Rotonda, in S. Campana, C. Felici, R. Francovich, F. Gabbrielli, op. cit. (n. 2), p. 423-435.

7 Per la definizione di 'inecclesiamento' si veda G. CANTINO WATAGHIN, Le fondazioni ecclesiastiche nelle vicende delle aree rurali: spunti di riflessione per l'occidente tardo antico (IV-V secolo), in Antiquité Tardive, 2, 2013, p. 189-204, in particolare a p. 191.

${ }^{8}$ Si vedano i vari contributi in S. Campana, C. Felici, R. Francovich, F. Gabbrielli, op. cit. (n. 2).

${ }_{9}$ C. VIOLANTE, Le strutture organizzative della cura d'anime nelle campagne dell'Italia centrosettentrionale (secoli V-X), in Cristianizzazione e organizzazione ecclesiastica delle campagne nell'Alto Medioevo: espansione e resistenze, XXVIII Settimana di Studio del CISAM (Spoleto, 10-16 aprile 1980), Spoleto, 1982, p. 963-1158.

${ }^{10}$ Non dobbiamo infatti dimenticare come Violante fosse uno storico e, soprattutto, come in quegli anni gli scavi di edifici di culto fossero scarsi nel territorio toscano, per non dire quasi assenti.

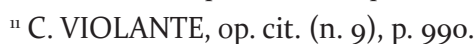


imminentes gladios evadere fugae praesidio niteretur, acutis sudibus occurrentia sibi septa transiliens, inferiore partes corporis inseruisse suggessit, quae vix adhibita curatione biennio potuissent abstergi $i^{12}$ : se da un lato, dunque, dalle parole del papa il panorama descritto sembrerebbe indubbiamente ritrarre un contesto in profonda crisi demografica, dall'altro, queste stesse parole risultano ancorate a stilemi retorici ben codificati e ripetitivi, per cui non necessariamente attendibili; non solo, l'aspetto più importante è determinato dal fatto che il papa, in realtà, non faccia alcun riferimento, né diretto né indiretto, alle 'fondazioni ecclesiastiche' ma, piuttosto, quest'ultime sembrerebbero inserite in maniera induttiva in tale sottofondo destrutturante dallo stesso Cinzio Violante. Sarebbe stato solo a partire dalla fine del VII-inizi dell'VIII secolo che si sarebbe articolata una rete ecclesiale progressivamente organizzata, gradualmente sviluppatasi grazie ad un ruolo sempre più incisivo da parte dei vescovi, secondo un esercizio di tipo 'eccettuativo' dei beni ecclesiastici, in cui gli episcopi avrebbero iniziato ad imporre diritti di tipo signorile e vassallatico, affermando una gestione, oltre che di carattere spirituale, anche di tipo temporale ${ }^{13}$.

Uno degli obiettivi di questa ricerca, pertanto, è quello di sottoporre a confronto la materialità del dato 'quantitativo-qualitativo'(fig. 2), emerso durante le attività di schedatura, con tale paradigma storiografico, che a lungo è stato (e in parte, è tuttora) pietra inamovibile nelle linee del dibattito: non solo, scopo ulteriore è la comprensione dei mutui rapporti tra città e campagne nella conduzione dello sviluppo dell'edilizia ecclesiastica, nel tentativo di comprendere se questa sia stata effettivamente 'ingrandita' dalla storiografia tout court, oppure se il ruolo della chiesa abbia costituito una parte integrante e pienamente partecipativa nella strutturazione dei paesaggi altomedievali, sia urbani che rurali. Di conseguenza, verranno passate in rassegna le principali tipologie ecclesiastiche sviluppatesi sia intra muros che extra urbem, dal IV al X secolo ${ }^{14}$, con particolare attenzione (ove possibile) ai contesti insediativi in cui si andarono ad inserire, alle conseguenze che a loro
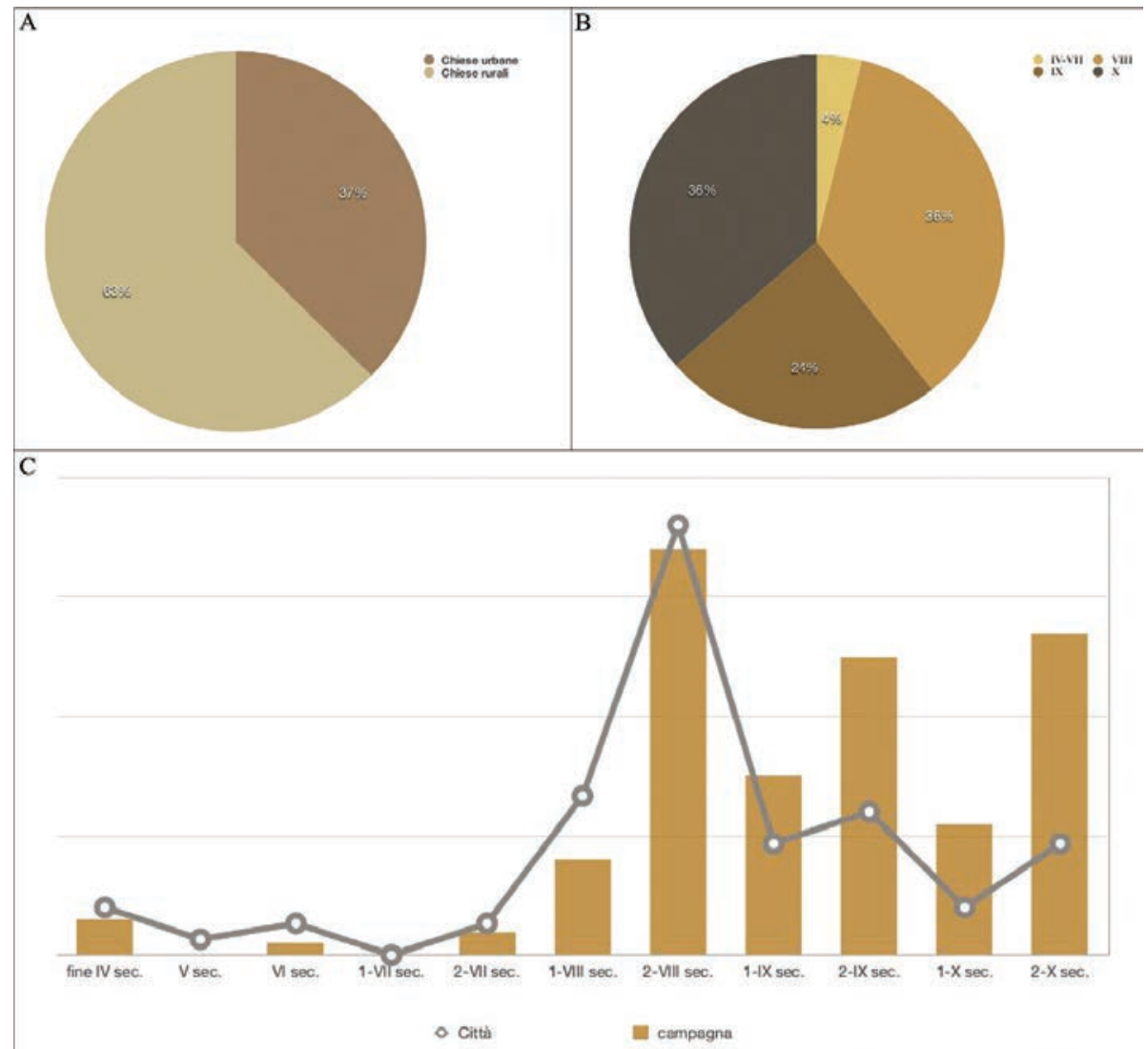

Fig. 2: A) rapporto percentuale tra chiese urbane e rurali nella schedatura B) rapporto percentuale tra le cronologie delle chiese schedate C) confronto tra le attestazioni di chiese in ambito rurale e urbano (elaboraz. a.).

volta ebbero su questi stessi bacini topografici e al valore politico-economico che le nuove fondazioni svolsero, il tutto coniugando un approccio che abbia nello "spessore dei numeri" ${ }^{15}$ il proprio punto fondante, senza però perdere di vista anche il portato informativo di tipo 'qualitativo' che $\mathrm{i}$ singoli contesti ci possono dare.

\section{LE CITTÀ. L'IMPATTO DELL'EDILIZIA CRISTIANA NEI QUADRI TOPOGRAFICI URBANI DAL IV AL X SECOLO}

In questa sede non ci si soffermerà dettagliatamente sui processi di metamorfosi cui andarono incontro le città della Tuscia settentrionale in età tardo antica ed alto medievale, argomento sul quale la bibliografia, anche recente, è piuttosto consistente $\mathrm{e}^{16}$, ma, piuttosto, ci si concentrerà in maniera più particolareggiata sull'influenza, dal punto

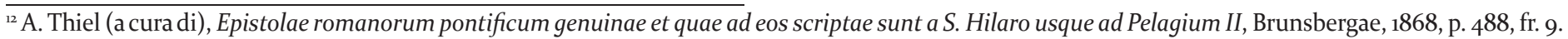
${ }^{13}$ C. VIOLANTE, op. cit. (n. 9), p. 1015-1016.

${ }^{14}$ Inizialmente l'alto medioevo, nel territorio toscano, vide l'ordinamento della Tuscia Langobardorum, il momento della cui strutturazione non è unanimemente riconosciuto da tutti gli studiosi, in quanto alcuni tendono ad identificarne la conformazione negli anni immediatamente successivi al 569 d.C. (P.M. CONTI, La Tuscia e i suoi ordinamenti territoriali nell'alto medioevo, in Atti del V Congresso Internazionale di Studi sull'Alto Medioevo, Spoleto, 1973, p. 61-116, in particolare a p. 99), mentre altri, invece, ne abbassano la cronologia agli inizi del VII secolo d.C. (A. DE CONNO, L'insediamento longobardo a Lucca, in G. Rossetti (a cura di), Pisa e la Toscana occidentale nel Medioevo. A Cinzio Violante nei suoi 7o anni, Pisa, 1991, p. 59-127). Il passaggio all'età carolingia, invece, è da attribuire probabilmente agli inizi del IX d.C. e, dunque, alcuni decenni più tardi del 'canonico' 774 , dal momento che, nelle città, fino alla fine dell'VIII e, in alcuni casi, ai primissimi anni del secolo successivo, si attestano ancora duces longobardi (H. KELLER, La Marca di Tuscia fino all'anno mille, in Atti del V Congresso Internazionale di Studi sull'Alto Medioevo, Spoleto, 1973, p. 117-140, p. 119).

${ }^{15}$ Sull'importanza di un approccio legato ad una base quantitativa come punto di partenza per la formulazione di modelli storici si veda M. VALENTI, La formazione dell'insediamento altomedievale in Toscana. Dallo spessore dei numeri alla costruzione di modelli, in G.P. Brogiolo, A. Chavarría Arnau, M. Valenti (a cura di), Dopo la fine delle ville: le campagne dal VI al IX secolo, XI Seminario sul Tardoantico e l'Altomedioevo, Mantova, 2005, p. 193-220. ${ }^{16}$ Specificamente per la Toscana, un contributo di sintesi ancora attuale e valido è rappresentato da G. CIAMPOLTRINI, Città "frammentate" e città fortezza. Storie urbane della Toscana centro-settentrionale fra Teodosio e Carlo Magno, in R. Francovich, G. Noyé (a cura di), La storia dell'alto medioevo italiano (VI-X secolo) alla luce dell'archeologia, Firenze, 1994, p. 615-633; più recentemente si vedano: C. CITTER, E. VACCARO, Le costanti dell'urbanesimo altomedievale in Toscana (secoli IV-VIII), in Atti del III Congresso Nazionale di Archeologia Medievale (Salerno, 2-5 ottobre 2003), Firenze, 2003, p. 309-313; 
di vista strutturale, topografico e politico-economico, che ebbe il cristianesimo - nelle proprie forme materiali e monumentali - sugli assetti urbani.

A livello generale, già nel corso del III-IV secolo d.C., la maggior parte delle città della Tuscia Annonaria attraversò a profonde riconfigurazioni dei propri assetti originari, ancora ancorati a tipologie edilizie ed organizzazioni topografiche tipiche dell'urbanesimo romano: a Lucca sono documentate prime tracce di abbandono di diversi contesti, tradotte nell'accumulo di livelli di accrescimento sui piani d'uso di alcune domus e nella presenza di fosse di spoliazione e buche di palo (si vedano i depositi stratigrafici di via Buia, Via San Paolino Via Burlamacchi, Via Galli Tassi, Via San Tommaso, Via S. Anastasio e Piazza del Duomo) ${ }^{17}$, così come avviene anche a Firenze, nelle riconversioni strutturali leggibili nel teatro e nell'anfiteatro, utilizzati come fronti di cava e in cui vennero inserite capanne in materiali deperibili $i^{18}$. Congiuntamente a tali fenomeni, però, l'urbanesimo tardo romano si delineò anche secondo modalità di profondo rinnovamento: già dalla seconda metà del III secolo d.C., infatti, a Lucca si registrano un importante opera di restauro delle mura ad opera dell'imperatore Probo ${ }^{19}$, la presenza di un curator rei publicae $^{20}$ e l'impianto di una fabbrica imperiale di spathae in piena età tetrarchica (Lucensis spatharia) ${ }^{21}$; a Firenze, nel medesimo torno cronologico, un grande impianto termale viene edificato nella zona di Porta S. Giovanni ${ }^{22}$ ed un fenomeno analogo si documenta anche a Volterra ove, sempre nel III secolo d.C., si ravvisa la messa in opera di due balnea a destinazione pubblica ${ }^{23}$, mentre anche a Pistoia, pur a fronte di scarsi dati archeologici, il III secolo viene considerato "un momento di vero e proprio sviluppo urbanistico"24.

Il III secolo, dunque, presentò una serie di riassestamenti nei comparti urbanistici delle città, in cui si alternarono fenomeni di parziale recessione ad altri di grande investimento infrastrutturale ${ }^{25}$, prodromi di quella che, a partire dalla fine del IV secolo d.C., divenne una vera e propria 'rivoluzione topografica', determinata dall'inserimento dell'edilizia legata al culto cristiano ${ }^{26}$ che, nell'arco di poco meno di due secoli (dalla fine del IV, appunto, sino al pieno VI), redistribuì completamente gli equilibri di fruizione e sfruttamento degli spazi intra muros e dei suburbia: in tale congerie storico-topografica, le tipologie di strutture ecclesiastiche che si affermarono nelle città furono sostanzialmente tre, ovverosia le grandi ecclesiae episcopales, le chiese devozionali ed, infine, i complessi funerari extra muros.

Per quanto concerne le ecclesiae vescovili (fig. 3), i casi meglio noti sono quelli di Lucca (dove il primo vescovo noto è attestato nel $343^{27}$ ) e Firenze (primo vescovo noto nel $313^{28}$ ): nel primo caso la chiesa (dedicata ai Santi Giovanni e Reparata) venne edificata alla fine del IV secolo, in un comparto periferico rispetto al profilo della città romana, nel quadrante sud-orientale, a ridosso della mura, sui resti di una preesistente domus (quantunque i resti di alcune suspensurae non ne escludano una precedente configurazione come impianto termale) ${ }^{29}$, articolandosi in una grande aula con planimetria a cruce commissa, scandita in tre nava-

F. CANTINI, C. CITTER, Le città toscane nel V secolo, in P. Delogu, S. Gasparri (a cura di), Le trasformazioni del V secolo. L'Italia, i barbari e l'Occidente romano, Turnhout, 2010, p. 401-427; C. CITTER, Archeologia delle città toscane nel medioevo (V-XV secolo). Fotogrammi di una complessità, Mantova, 2012; G. CASTIGLIA, Lucca e Siena a confronto: trasformazioni urbane nella Tuscia Annonaria dall'età classica alla fine dell'altomedioevo, in Mélanges de l'École française de Rome - Moyen Âge 128-1, 2016 (https://mefrm.revues.org/2870).

${ }^{17}$ E. ABELA, Lucca, in S. Gelichi (a cura di), Archeologia urbana in Toscana. La città altomedievale, Mantova, 1999, p. 23-44.

${ }^{18}$ R. FRANCOVICH, E. SCAMPOLI, F. CANTINI, J. BRUTTINI, La storia di Firenze tra tarda antichità e medioevo. Nuovi dati dallo scavo di Via de' Castellani, in Annali di storia di Firenze, 2, 2007, p. 9-48.

${ }^{19}$ CIL XI, 204.

${ }^{20}$ Menzionato in un'epigrafe, pubblicata per la prima volta in L'année èpigraphique del 1965, n. 244.

${ }^{21}$ Not. Dign., Oc., IX-29 (Notitia Dignitatum et administrationum omnium tam civilium quam militarium = C. Neira Faleiro (a cura di), La Notitia Dignitatum: nueva edición crítica y comentario histórico, Roma, 2005).

${ }^{22}$ GA. MAETZKE, L'episcopio: testimonianze archeologiche dai vecchi scavi in Piazza San Giovanni, in D. CARdini (a cura di), Il bel San Giovanni e Santa Maria del Fiore. Il Centro religioso di Firenze dal Tardo Antico al Rinascimento, Firenze, 1996, p. 179-189; R. MIRANDOLA, Firenze, in S. Gelichi, op. cit. (n. 17), p. 59-72 (p. 62).

${ }^{23}$ Per i due impianti termali realizzati a Volterra nel III secolo d.C. si vedano M. MUNZI, G. RICCI, M. SERLORENZI, Volterra tra tardoantico e altomedioevo, in Archeologia medievale, 21, 1994, p. 639-656 e A. ALBERTI, Volterra, in S. Gelichi, op. cit. (n. 17), p. 73-85.

${ }^{24}$ G. VANNINI, Pistoia altomedievale. Una rilettura archeologica, in E. Vannucchi (a cura di), Pistoia e la Toscana nel Medioevo. Studi per Natale Rauty, Pistoia, 1997, p. 37-54 (p. 44).

${ }_{25}$ Una recente ed importante riflessione sul III secolo, volta anche a ridimensionarne parzialmente un'interpretazione univocamente 'catastrofista', si ha in S. ESMONDE CLEARY, The Roman West, AD 200-500. An Archaeological Study, Cambridge, 2013, in particolare alle p. 18-41.

${ }^{26}$ Sulla formazione della topografia cristiana come elemento di maggiore impatto e novità negli assetti urbanistici tardo antichi si vedano P.A FÉVRIER, Permanence et héritages de l'antiquité dans la topographie des villes de l'Occident durant le Haut Moyen Âge, in Topografia urbana e vita cittadina nell'alto medioevo in Occidente (XXI settimana di studio CISAM, 26 aprile-1 maggio 1973), Spoleto, 1974, p. 41-138; N. GAUTHIER, La topographie chrétienne entre idéologie et pragmatisme, in G.P. Brogiolo, B. Ward-Perkins (a cura di), The Idea and Ideal of the Town between Late Antiquity and the Early Middle Ages, Leiden, 1999, p. 195-209 e PH. PERGOLA, Dalla città classica alla città cristiana in Occidente. Le mutazioni della civitas nella christiana Respublica, in F. Bisconti, O. Brandt (a cura di), Lezioni di archeologia cristiana, Città del Vaticano, 2014, p. 137-206 (ivi bibl.).

${ }^{27}$ HILARIUS PICT., Fragm. Hist., B, II, 4,15 (Maximus a Tuscia de Luca); PBCE, p. 1465 (PBCE = Ch. Pietri, L. Pietri (a cura di), Prosopographie Chrétienne du Bas-Empire 1-2. Prosopographie de l'Italie Chrétienne (313-604), Roma, 1999); F. LANZONI, Le diocesi d'Italia, dalle origini al principio del secolo VII, Faenza, 1927 p. 590.

${ }_{28}^{28}$ J.D. MANSI, Sacrorum Conciliorum nova et amplissima collectio, Firenze-Venezia, 1759-1798 (riproduzione anastatica: Graz, 1960), vol. II, p. 438 (Felix a Florentia Tuscorum); PBCE, p. 769; F. LANZONI, op. cit. (n. 26), p. 578.

${ }^{29}$ Sugli scavi nel plesso della cattedrale, sulla longue durée, si rimanda ai vari contributi presenti in G. Piancastelli Politi Nencini (a cura di), La chiesa dei Santi Giovanni e Reparata in Lucca. Dagli scavi archeologici al restauro, Lucca, 1992, a J.A. QUIRÒS CASTILLO, L'architettura altomedievale lucchese: la chiesa dei Santi Giovanni e Reparata in Lucca, in Archeologia dell'architettura, 5, 2001, p. 131-154 e a J.A. QUIRÒS CASTILLO, Modi di costruire a Lucca nell'altomedioevo. Una lettura attraverso l'archeologia dell'architettura, Firenze, 2002, in particolare alle p. 23-45. 


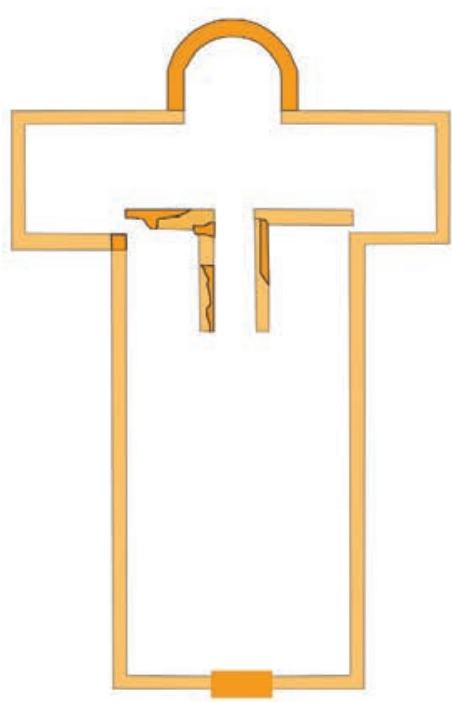

SS. Giovanni e Reparata (Lucca)

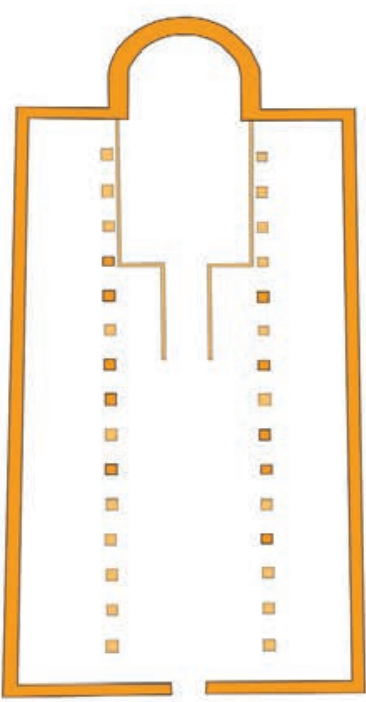

S. Reparata (Firenze)

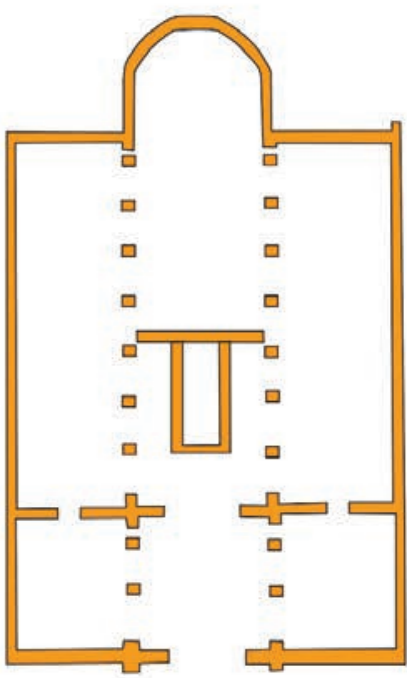

S. Maria (Luni)

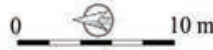

Fig. 3: planimetria delle principali ecclesiae episcopales note archeologicamente, nelle loro fasi tardo antiche (elaboraz. a.).

te ${ }^{30}$ ed impreziosita da una pavimentazione musiva ${ }^{31}$; nel medesimo torno cronologico, anche a Firenze l'impianto dell'originaria ecclesia episcopalis, con dedica a Santa Reparata $^{32}$, sorse in ambito periferico, nella zona nord-orientale della città, a ridosso della cinta muraria di età romana, sui

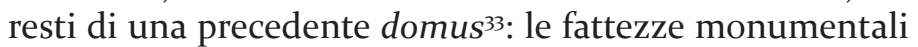
della Santa Reparata fiorentina si caratterizzano per una grande aula a tre navate ( $52 \times 35 \mathrm{~m} \mathrm{ca}$.), impreziosita da una pregevole pavimentazione mosaicata ${ }^{34}$.
Estremamente più complessa è invece l'interpretazione del complesso episcopale pisano (a Pisa il primo episcopus si attesta nelle fonti nel 31355): con pochi dubbi la sua collocazione topografica è da ascrivere alla zona del celebre Campo dei Miracoli, insistente in un'area marginale della città, posta a nord-ovest, interessata da numerosi interventi di scavo, sin dagli anni Cinquanta del XX secolo, con Piero Sanpaolesi ${ }^{36}$, poi ripresi negli anni Duemila ${ }^{37}$. La frammentazione delle indagini archeologiche (e soprattutto la carenza di metodo

\footnotetext{
${ }^{30}$ Rimane ancora dibattuta l'originaria articolazione a tre navate o meno: su questo aspetto si vedano G. CIAMPOLTRINI, L'area di S. Giovanni e S. Reparata nell'assetto urbano d'età romana, in G. Piancastelli Politi Nencini (a cura di), op. cit. (n. 29), p. 191-196; L. PANI ERMINI, Le fasi altomedievali [aula], Ibidem, p. 49-77; J. A. QUIRÒS CASTILLO, op. cit. (2001 e 2002, n. 29).

${ }^{31}$ G. CIAMPOLTRINI, La cattedrale di Santa Reparata a Lucca. Per un riesame delle pavimentazioni musive del IV secolo, in H. Mohrlier (a cura di.), La Mosaïque gréco-romaine IX, I, Roma, 2005, p. 109-121.

${ }^{32}$ A margine bisogna però sottolineare come gli studiosi non siano concordi nell'attribuire al complesso di Santa Reparata, identificato al di sotto dell'attuale Duomo, la dignità di prima ecclesia episcopalis fiorentina: in letteratura, anzi, nella maggior parte dei casi tale ruolo è quasi sempre proposto per la suburbana chiesa di San Lorenzo. I sostenitori di questa pista esegetica basano il proprio assunto sul fatto che quest'ultima fosse stata dedicata da S. Ambrogio in persona (Paolino di Milano nella sua Vita Ambrosii la definisce Basilica Ambrosiana: PAUL. MED., Vita Ambr, 50, 1-10), che fu invitatus a Florentinis ad Tusciam (PAUL. MED., Vita Ambr, 27, 3-4) e che, proprio in questa occasione, avrebbe pronunciato la sua celebre orazione Exhortatio virginitatis (AMBR., Exhort. virg., II, 10). A favore di questa tesi si sono espressi: A. ADEMOLLO, Marietta de' Ricci. Ovvero Firenze al tempo dell'assedio racconto storico, Firenze, 1845, p. 899-900; R. DAVIDSOHN, Storia di Firenze, I. Le origini, Firenze,1956 (ed. originale 1896), p. 54; G. ANICHINI, Sant'Ambrogio e la chiesa di Firenze, in Ambrosiana. Scritti di storia, archeologia ed arte pubblicati nel XVI centenario della nascita di Sant'Ambrogio, Milano, 1942, p. 339-347; GU. MAETZKE, Considerazioni sugli scavi di piazza del Duomo di Firenze, in P. Dal Poggetto (a cura di), Scritti di storia dell'arte in onore di Ugo Procacci, Milano, 1977, p. 55-60; L. PANI ERMINI, Firenze, in P. TESTINI, G. CANTINO WATAGHIN, L. PANI ERMINI, La cattedrale in Italia, in Actes du XI CIAC, Rome (= Lyon, Vienne, Grenoble, Genève, Aoste), Città del Vaticano, 1989, p. 122-126; G. VANNINI, Florentia: Archeologia di una città medievale, in V. d'Aquino, G. Guarducci, S. Nencetti, S. Valentini (a cura di), Archeologia a Firenze: Città e Territorio. Atti del Workshop (Firenze, 12-13 Aprile 2013), Oxford, 2015, p. 71-81; G. VANNINI, E. SCAMPOLI, Florentia paleocristiana tra tardoantico e altomedioevo: un quadro topografico, in R.M. Carra Bonacasa, E. Vitale (a cura di), La cristianizzazione in Italia tra tardoantico e altomedioevo, Atti del IX Congresso Nazionale di Archeologia Cristiana (Agrigento, 20-25 novembre 2004), Palermo, 2007, p. 843-868, mentre una posizione più sfumata è in R. MIRANDOLA, Firenze, in S. Gelichi (a cura di), op. cit. (n. 17), pp. 59-72. Chi scrive, invece, sposa la lectio di R. Farioli Campanati (R. FARIOLI CAMPANATI, Note sulla primitiva cattedrale di Firenze: il problema dell'intitolazione, in Annali della Scuola Normale Superiore di Pisa, III (V-2), 1975, p. 535-554), che identificò proprio in Santa Reparata i resti della prima ecclesia episcopalis, basandosi su una rigorosa e puntuale analisi delle fonti scritte: la posizione topografica ed i resti materiali, soprattutto se confrontati per dimensioni e pregio con le altre chiese vescovili coeve, su tutte quella di Lucca, infatti, lasciano pochi dubbi sul primigenio ruolo episcopalis di Santa Reparata, soprattutto a fronte di una collocazione suburbana del San Lorenzo e di una totale assenza di emergenze archeologiche a quest'ultima pertinenti.

33 Sugli scavi al di sotto del Duomo fiorentino si vedano F TOKER, Scavi del complesso altomedievale di Santa Reparata sotto il Duomo di Firenze, in Archeologia medievale, 2, 1975, p. 161-19o; F. TOKER, Florence Cathedral: the Design Stage, in The Art Bulletin, 6o-II, 1978, p. 214-231 ed il recente F. TOKER, Archaeological Campaigns below the Florence Duomo and Baptistery, 1895-1980, Turnhout, 2013.

${ }^{34}$ Si vedano TOKER 1975, op. cit. (n. 33) e TOKER 2013, op. cit. (n. 33).

35 J. D. MANSI, op. cit. (n. 28), vol. II, p. 438 (Gaudentius a Pisis); PBCE, 886-887; F. LANZONI, op. cit. (n. 26), p. 585.

${ }^{36}$ P. SANPAOLESI, Il duomo di Pisa e l'architettura romanica toscana delle origini, Pisa, 1975.

${ }^{37}$ A. Alberti, E. Paribeni (a cura di), Archeologia in Piazza dei Miracoli. Gli scavi 2003-2009, Pisa, 2011.
} 
stratigrafico negli interventi del Sanpaolesi, inevitabile considerato il momento storico) non ha consentito di avere una complessiva e rigorosa possibilità di lettura del deposito e, ad ogni modo, non sono state intercettate tracce materiali ascrivibili con certezza alla prima ecclesia episcopalis. Un primo dato di grandissimo interesse, però, riguarda la presenza in quest'area di un gran quantitativo di emergenze attribuibili chiaramente a un insieme di domus con più fasi, sia di età repubblicana, ma anche con importanti rifacimenti di epoca tardo antica, che la connotano, evidentemente, come zona a chiarissima destinazione residenziale ${ }^{38}$. Per quanto attiene, invece, lo sviluppo del 'quartiere cristiano', i lacerti di alcune murature identificati dal Sanpaolesi sono stati, pur con la dovuta prudenza, attribuiti da F. Redi ad un'ipotetica prima fase della chiesa mater ${ }^{39}$, sebbene la ripresa degli scavi abbia portato, agli inizi degli anni Duemila, grazie anche a nuove evidenze, a riconnettere le medesime murature ad un edificio ecclesiastico 'pre-romanico' ${ }^{40}$; dati controversi attengono anche al battistero, insistente nella medesima area, anch'esso lungamente dibattuto ma che, grazie ad un attento riesame, sembrerebbe ormai potersi ritenere ascrivibile ad una cronologia di pieno VI secolo ${ }^{41}$. La zona del Campo dei Miracoli, inoltre, sin da età tardo antica e, soprattutto, durante la frequentazione longobarda, fu interessata da una destinazione funeraria, come ben certificano le sepolture identificate a più riprese ${ }^{42}$; tutti questi dati (e, non ultima, la 'continuità topografica che in quest'area avrebbe portato all'edificazione della cattedrale 'buschetiana' nell'XI secolo), dunque, lasciano comunque pochi dubbi sulla presenza in questo comparto urbano del nucleo episcopale originario.

Pur non rientrando precipuamente nell'area di studio di chi scrive, non si può non menzionare anche il caso del complesso episcopale di Luni (ove il primo vescovo storicamente accertato risale al $465^{43}$ ), sia per la sua importanza intrinseca, sia per la stretta vicinanza geografico-politica con le città di nostro diretto interesse: anche nel caso lunense la prima fase dell'ecclesia episcopalis si impostò, agli inizi del V secolo, sui resti di un'importante domus, nota per lo splendido mosaico di Oceanus ${ }^{44}$, subendo una significativa opera di ampliamento ed abbellimento nel VI, molto probabilmente per mano del famulus Christi Gerontius, come attesta l'epigrafe musiva apposta nel rifacimento pavimentale attribuito a questa fase ${ }^{45}$.

Per quanto concerne Pistoia (primo vescovo attestato nel $492^{46}$ ) e Fiesole ${ }^{47}$ (primo vescovo attestato sempre nel $492^{48}$ ), invece, in entrambi i casi non si hanno dati riconducibili alle prime ecclesiae episcopales, sebbene per Pistoia si possa comunque ipotizzare plausibilmente che, se essa fosse effettivamente sorta in corrispondenza dell'attuale duomo, come ritengono i più ${ }^{49}$, anche in tal caso saremmo di fronte alla rioccupazione di un'area precedentemente interessata dalla presenza di un complesso di domus ${ }^{50}$.

Passando ora all'analisi delle altre tipologie di edifici di culto cristiano che si andarono ad innestare nei tessuti urbani delle civitates tardo antiche della Tuscia Annonaria, abbiamo già chiosato in precedenza come esse siano riconoscibili sia in chiese urbane - che potremmo definire 'devozionali' - che negli edifici suburbani a destinazione funeraria (che, però, è importante rimarcare come evidentemente dovettero essere polifunzionali, soddisfacendo anche alle canoniche esigenze liturgiche delle comunità). Nel primo caso, sfortunatamente, i dati archeologici a nostra disposizione sono piuttosto scarsi, concretizzandosi quasi esclusivamente nella grande basilica fiorentina di Santa Cecilia, identificata nel corso degli scavi realizzati in Piazza della Signoria ${ }^{51}$ : si tratta di un edificio, sfortunatamente datato dagli scavatori in una forchetta cronologica molto ampia (tra la fine del IV ed il pieno VI secolo d.C.) e sorto in un'area precedentemente a destinazione residenziale

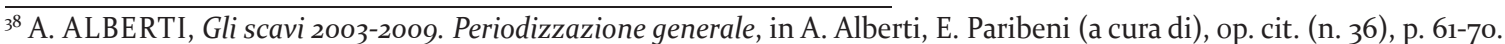

39 F. REDI, Pisa com'era: archeologia, urbanistica e strutture materiali (secoli V-XV), Napoli, 1991, p. 64-76.

${ }^{40}$ A. ALBERTI, L. PARODI, J. MITCHELL, La cattedrale prima di Buscheto, in A. Alberti, E. Paribeni (a cura di), op. cit. (n. 36), p. $243-267$.

${ }^{41}$ L. Pani Ermini, D. Stiaffini (a cura di), Il battistero e la zona episcopale di Pisa nell'altomedioevo, Ospedaletto, 1985.

${ }^{42}$ Per una sintesi sull'area funeraria, le singole tombe ed i corrispettivi corredi, si rimanda a A. ALBERTI, M. BALDASSARRI, A. FORNACIARI, L'area episcopale e l'organizzazione della necropoli tra VI e VII secolo, in A. Alberti, E. Paribeni (a cura di), op. cit. (n. 36), p. 195-242.

${ }^{43}$ HILARIUS, Ep., XV-1; PCBE, p. 777.

${ }^{44}$ I. VAY, I mosaici della domus tardoantica di Oceano sottostante la cattedrale di Luni, in Atti del III colloquio dellassociazione italiana per lo studio e la conservazione del mosaico, Bordighera, 1996, p. 25-38.

${ }^{45} \mathrm{Si}$ veda, con bibliografia, S. LUSUARDI SIENA, Gli scavi nella cattedrale di Luni nel quadro della topografia cittadina tra tarda antichità e medioevo, in M. Marcenaro (a cura di), Roma e la Liguria Maritima: secoli IV-X. La capitale cristiana e una regione di confine, Atti del Corso e Catalogo della Mostra (Genova, 14 febbraio-31 agosto 2003), Bordighera, 2003, p. 195-202.

${ }^{46}$ Regesta Pontificum Romanurum, p. 94, fr. 735, (Quod a Pistoriensi, Lucensi, Faesulano Episcopis factum scribit); F. LANZONI, op. cit. (n. 26), p. 584.

${ }_{47}$ M. C. FAVILLA, Fiesole, in S. Gelichi (a cura di), op. cit. (n. 17), p. 45-58.

${ }^{48}$ J.D. MANSI, op. cit. (n. 28), vol. VIII, p. 127 (pontifices Pistoriensis, Lucensis, et Fesulanus); si veda anche Regesta Pontificum Romanurum, p. 94, fr. 735, dove si ha una menzione leggermente differente (Quod a Pistoriensi, Lucensi, Faesulano Episcopis factum scribit); F. LANZONI, op. cit. (n. 26), p. 583.

${ }^{49}$ S. FERALLI, Aenigmata Pistoriensia, in Bullettino Storico Pistoiese, 5, 1962, p. 5-20; G. CAPECCHI, G. DE TOMMASO, Per la più antica storia della cattedrale pistoiese, in Bullettino Storico Pistoiese, 84, 1982, p. 7-36; N. RAUTY, Storia di Pistoia, I. Dall'alto medioevo all'età precomunale (406-1105), Firenze, 1988; G. VANNINI, Pistoia altomedievale. Una rilettura archeologica, in E. Vannucchi (a cura di), Pistoia e la Toscana nel Medioevo. Studi per Natale Rauty, Pistoia, 1997, p. 37-54; M. GIANNINI, La basilica episcopale paleocristiana di Pistoia: ipotesi e nuove prospettive di studio, in Orizzonti. Rassegna di Archeologia, 7, 2006, Pisa, p. 129-140.

${ }^{50}$ Sugli scavi realizzati in piazza duomo e le interpretazioni dei vari piani pavimentali identificati, attribuiti a diverse fasi di utilizzo delle domus, si vedano in particolare FERALLI, op. cit. (n. 49), RAUTY, op. cit. (n. 49), in particolare a p. 56 e M. GIANNINI, op. cit. (n. 49).

${ }^{51}$ Per un sunto sugli scavi in Piazza della Signoria si rimanda a G. DE MARINIS, Archeologia urbana a Firenze: piazza della Signoria, in G. Capecchi (a cura di), Alle origini di Firenze. Dalla preistoria alla città romana, Firenze, 1996, p. 49-56 (ivi bibl.). La dedica a S. Cecilia è in realtà attestata solamente dal X secolo d.C. (La dedica a Santa Cecilia è citata negli anni 929-931 d.C. [ASF, Bullettone, p. 316] e negli anni 929-964 d.C. [ASF, Bullettone, p. 319]), ma in letteratura ormai anche per la fase tardo antica viene utilizzata, per comodità, tale definizione (ASF = Archivio di Stato di Firenze).
} 
ed artigianale, che si doveva articolare in un'ampia aula a tre navate, con al centro una solea ${ }^{52}$. Gli scavi, però, hanno consentito di identificarne solamente l'ambito orientale, per cui la ricostruzione icnografica della basilica è in gran parte ipotetica, ma, ad ogni modo, ci consente di identificarla come un importantissimo polo devozionale insistente nella zona meridionale della Florentia tardo antica, sorta di contraltare a Santa Reparata, posta a nord.

Più consistenti sono, invece, le informazioni che possiamo trarre dagli edifici posti nei suburbia, dove ancora una volta sono Lucca e Firenze a restituire i dati più completi ed interessanti; a Lucca, nella zona posta immediatamente all'esterno delle mura settentrionali, alla fine del IV sorse la chiesa dedicata a San Frediano, edificata in un contesto precedentemente interessato da una necropoli in uso fino almeno al III secolo: scavi archeologici realizzati nel 1989 hanno consentito di mettere in luce parte di un edificio a pianta cruciforme ${ }^{53}$, la cui destinazione era legata sia ad una coeva area funeraria che all'assolvimento della prassi liturgica, al punto che nel corso dell'alto medioevo la chiesa risulta compresa nel novero delle strutture 'sedali', legate al cerimoniale pasquale ${ }^{54}$. A Firenze, invece, nel suburbium meridionale, oltre il corso del fiume Arno venne edificata agli inizi del $\mathrm{V}$ secolo una chiesa funeraria, intitolata a Santa Felicita, anch'essa impostata sulle preesistenze di un cimitero di età imperiale: si tratta di un edificio absidato e orientato, probabilmente mononave ${ }^{55}$, la cui peculiarità sta nel fatto che, come ben testimoniano le numerose epigrafi pavimentali rinvenute ancora in situ ${ }^{56}$, fosse destinata ad accogliere una comunità di orientali, soprattutto siriani, ragionevolmente acquartierata lungo il corso del fiume per motivi commerciali.

Plausibilmente una destinazione funeraria (oltre che devozionale) dovette avere anche il San Lorenzo, ritenuto da molti la primigenia ecclesia episcopalis fiorentina (vedi supra, nota n. 32), che sorse su un contesto di più antiche tabernae ${ }^{57}$ (e, dunque, in un quartiere produttivo-commerciale): come abbiamo già evidenziato, non sono mai stati intercettati resti materiali della basilica, ma la sua posizione suburbana ci autorizza a non escludere che possa avere avuto una funzione cimiteriale, soprattutto in virtù del fatto che sappiamo, ancora una volta da Paolino da Milano, che qui sant'Ambrogio fece deporre le reliquie di San Agricola ${ }^{58}$, aspetto che molto plausibilmente potrebbe avere ingenerato un significativo culto ed una conseguente volontà, da parte della comunità fiorentina, di farsi inumare ad sanctum.

Il progressivo strutturarsi di una topografia cristiana ormai pienamente definita in tutte le proprie istanze principali, dunque, rappresenta il motore di pieno e principale rinnovamento dei profili urbani tardo antichi, che pure risultano in profondo riassestamento rispetto agli equilibri tipici della civitas romana. Come bene evidenziato anche di recente ${ }^{59}$, le città del territorio corrispondente all'attuale Toscana espressero le proprie evoluzioni in modalità differenti, con una linea di demarcazione piuttosto netta ed evidente tra la parte settentrionale, la Tuscia Annonaria, e quella meridionale, la Tuscia Suburbicaria, ove nella prima i fenomeni di crisi e recessione che si ingenerarono quasi trasversalmente nei centri urbani del Mediterraneo post classico ${ }^{60}$ risultarono molto meno incisivi e destrutturanti che nella seconda. L'istituzione della Tuscia Langobardorum, conformatasi ufficialmente alla fine del VI-inizi del VII secolo ${ }^{61}$, se indubbiamente comportò un notevole stravolgimento dal punto di vista politico-istituzionale, per quanto concerne l'edilizia ecclesiastica, invece, sia in città ma anche nelle campagne non ebbe ricadute significative per tutto il VII secolo, fino ad una vera e propria esplosione che caratterizzerà, di contro, l'VIII, soprattutto nella sua seconda metà.

È infatti sufficiente dare uno sguardo ai dati quantitativi proposti nel grafico per verificare l'assoluta penuria di fondazioni ecclesiastiche nel secolo VII (fig. 2): ovviamente, tale aspetto potrebbe dipendere semplicemente dalla carenza di fonti scritte note e, al contempo, dalla scarsità di indagini stratigrafiche già evidenziata in apertura, ma, in realtà, chi scrive ritiene che questo momento di assestamento potrebbe invece essere legato al fatto che con il VI secolo, de facto, la domanda-necessità di edifici ecclesiastici potesse ormai essersi temporaneamente esaurita. Di conseguenza, saremmo autorizzati ad ipotizzare che il VII secolo possa essere stato più che altro un momento di 'transizione', in una fase in cui si stava andando incontro ad una progressiva

\footnotetext{
${ }^{2}$ Si vedano DE MARINIS 1996, op. cit. (n. 51), VANNINI, SCAMPOLI, op. cit. (n. 32) e G. GUIDONI, Scavi e scoperte di archeologia cristiana in Toscana dal 1983 al 1993, in E. Russo (a cura di), 1983-1993: dieci anni di archeologia cristiana in Italia, Atti del VII Congresso Nazionale di Archeologia Cristiana (Cassino, 20-24 settembre 1993), Cassino, 2003, p. 249-266.

53 Per gli scavi del plesso si veda G. CIAMPOLTRINI, P. NOTINI, Lucca tardoantica e altomedievale: nuovi contributi archeologici, in Archeologia medievale, 17,1990, p. 561-592.

${ }^{54} \mathrm{MD} / \mathrm{V}$, n. 539, anno 838 d.C.: abentem eccl. S. Fridiani [...] et imperantem sicut in ceteris Ecclesiis sedalibus (MD/V = D. Barsocchini (a cura di), Raccolta di documenti per servire all'istoria ecclesiastica lucchese, in Memorie e documenti per servire all' istoria del ducato di Lucca, Lucca, 1837-1841).

55 GU. MAETZKE, Resti di basilica cimiteriale sotto Santa Felicita, in Notizie degli scavi di antichità, 11, 1957, p. 282-324.

$5^{56}$ La più antica di esse è datata al 405 d.C. ed era di un certo Theoteknos (GU. MAETZKE 1957, op. cit. (n. 55), p. 310).

57 GU. MAETZKE, Considerazioni sugli scavi di piazza del Duomo di Firenze, in P. Dal Poggetto (a cura di), Scritti di storia dell'arte in onore di Ugo Procacci, Milano, 1977, p. 55-6o.

${ }^{58}$ PAUL. MED., Vita Ambr, 29, 1-7 (In eadem civitate [Firenze, n.d.a.] basilicam constituit, in qua deposuit reliquias martyrum Vitalis et Agricolae, quorum corpora in Bononiensi civitate levaverat: posita enim erant corpora martyrum inter corpora Iudaeorum, nec erat cognitum populo Christiano, nisi se sancit martyres sacerdoti ipsius ecclesiae revelassent. Quae cum deponentur sub altari, quod est in eadem basilica constitutum, magna illic totius plebis sanctae laetitia atque exsultatio fuit, poena daemonum confitentium martyrum merita).

${ }^{59}$ F. CANTINI, C. CITTER, Le città toscane nel V secolo, in P. Delogu, S. Gasparri (a cura di), Le trasformazioni del V secolo. L'Italia, i barbari e l'Occidente romano, Turnhout, 2010, p. 401-427.

${ }^{60}$ A livello di sintesi generale sulla formazione delle città post classiche nel Mediterraneo si rimanda (ivi bibl.) a G.P. BROGIOLO, Le origini della città medievale, Mantova, 2011.

${ }^{61}$ Come già sottolineato, non è noto il momento esatto di strutturazione ufficiale della Tuscia Langobardorum: sulle varie ipotesi puntuali si rimanda al datato ma importante contributo di P.M. CONTI, op. cit. (n. 14).
} 

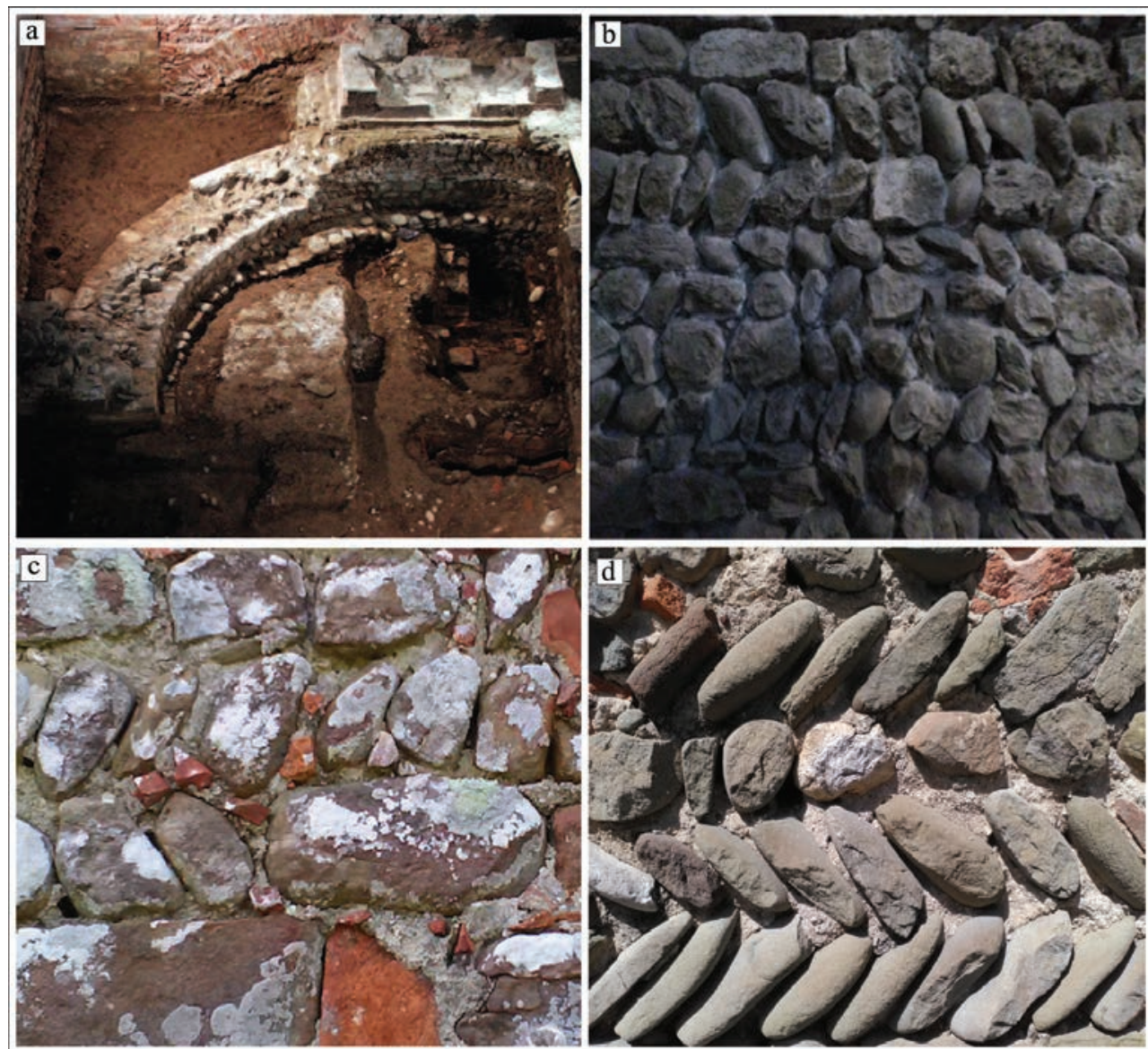

Fig. 4: esempi di tecnica muraria a 'spina di pesce' da Lucca e territorio. A) S. Ponziano (da CIAMPOLTRINI 2014); B) SS. Giovanni e Reparata (foto a.); C) S. Giusto a Marlia (foto a.); D) S. Martino in Ducentola (foto a.) a Lucca (sede di ducato nell'ambito della Tuscia Langobardorum), più di settanta nuove chiese, che proprio nell'VIII secolo raggiungono l'apice quantitativo.

Uno degli aspetti di maggior rilievo legato agli sviluppi dell'edilizia cristiana nell'alto medioevo lucchese, inoltre, è determinato dal trasferimento del rango di ecclesia episcopalis da Santa Reparata alla vicina San Martino, fatto noto già nel $724^{64}$, ma, plausibilmente, da rimandare ad alcuni anni prima: si trattò di un avvenimento di grande impatto, in primis perché i due edifici si trovavano a poche decine di metri di distanza l'uno dall'altro, nel medesimo bacino topografico in cui insistevano anche la curtis regia ${ }^{65}$, il palatium ${ }^{66}$ e, probabilmente, la zecca $^{67}$, dando pertanto origine (o meglio, potenziando una realtà già in essere dai secoli post romani) ad un 'quartiere cristiano' e, al contempo, centro del potere temporale, in cui, oltre alle chiese dei Santi Giovanni e Reparata e San Martino, si dislocava pure l'ecclesia Domini et Salvatoris et Sancti Petri infra civitatem nostra Luc. prope eccl. S. Martini ${ }^{68}$. La riconriorganizzazione delle forme demiche ${ }^{62}$, sulla lunga onda della destrutturazione dei paesaggi 'romani', mentre fu solo dall'VIII secolo che i nuovi possesores sarebbero divenuti una classe ormai stabilizzata ${ }^{63}$. Non sembra essere casuale che proprio con l'VIII secolo si assista ad una vera e propria esplosione di fondazioni ecclesiastiche nelle città e nei suburbia (si rimanda ancora ai grafici in fig. 2): il dato quantitativo è evidentemente di grandissimo rilievo, soprattutto se comparato con i secoli precedenti, e non può essere spiegato esclusivamente con il fatto che proprio a partire dall'VIII secolo si siano conservate molte più fonti scritte, in particolar modo a Lucca che, dall'VIII al X-XI secolo, costituisce senza dubbio il centro con il bacino di informazioni legate alle fondazioni ecclesiastiche di gran lunga più ricco; basti pensare che in tale torno cronologico si attestino, proprio figurazione del profilo urbano della Lucca di VIII secolo passò inoltre per l'importante cantiere della chiesa di San Michele in Foro, sorta nel corso medesimo secolo ${ }^{69}$, come ben evidenzia il toponimo, in corrispondenza del foro della colonia romana, quantunque la carenza di indagini archeologiche non consenta di verificare il rapporto fisico tra il preesistente spazio pubblico e l'edificio di culto, ovverosia se quest'ultimo si fosse andato ad impiantare direttamente sul piano d'uso originario del foro, oppure su eventuali livelli di accrescimento delle quote di frequentazione della città.

Un peculiarità delle fasi della Lucca altomedievale è, inoltre, sia in ambito urbano che immediatamente suburbano, l'elevato numero di fondazioni di monasteri (come quello dotato dell'ecclesia Domini et Salvatoris, fondato

\footnotetext{
${ }^{62}$ M. VALENTI, op. cit. (n. 6), p. 94.

${ }^{63} \mathrm{G}$. TABACCO, La connessione fra potere e possesso nel regno franco e nel regno longobardo, in I problemi dell'Occidente nel secolo VIII. XX Settimana di studio del Centro Italiano di Studi sull'Alto Medioevo, Spoleto, 1973, p. 133-168; M. VALENTI, op. cit. (n. 6).

${ }^{64} \mathrm{Nel} 724$ d.C. la chiesa di San Martino è infatti attestata per la prima volta con il rango di chiesa vescovile: ecclesia S. Martini in Episcopio: CDL, I, n. 114; $C D L=$ L. Schiaparelli (a cura di), Codice diplomatico longobardo, I, Roma, 1929 (Fonti per la storia d'Italia).

${ }_{55}$ Attestata la prima volta nel 754 d.C. come curte domni regis (CDL, I, n. 113).

${ }^{66}$ Per quanto concerne il palatium, però, si impone un ampio margine di prudenza, dal momento che esso è attestato per la prima volta solamente nel 1055 d.C., come palatium quod est sala imperatoris (RCL, I, n. 257 = P. Guidi, O. Parenti (a cura di), Regesta Chartarum Italiae. Regesto del capitolo di Lucca, I, Roma, 1910).

${ }^{67}$ Sulla zecca si veda (ivi bibl.) G. BELLONI, La zecca di Lucca dalle origini a Carlo Magno, in Le zecche minori toscane fino al XIV secolo (Atti del III Convegno Internazionale di Studi: Pistoia, 16-19 settembre 1967), Bologna, 1975, p. 91-106.

${ }^{68}$ Attestata nel 797 d.C. (MD/V, nn. 261, 262).

${ }^{69}$ San Michele in Foro viene menzionata nelle fonti per la prima volta nel 795 d.C. (MD/IV, n. 115 - MD/IV = D. Bertini (a cura di), Raccolta di documenti per servire all'istoria ecclesiastica lucchese, in Memorie e documenti per servire all' istoria del ducato di Lucca, Lucca, 1836). Analisi di lettura stratigrafica degli elevati realizzate nella cripta hanno dimostrato, anche dal punto di vista materiale, una prima fase attribuibile al pieno VIII secolo d.C. (J.A. QuIRòs CASTILlO 2002, op. cit. (n. 29), pp. 52-58).
} 


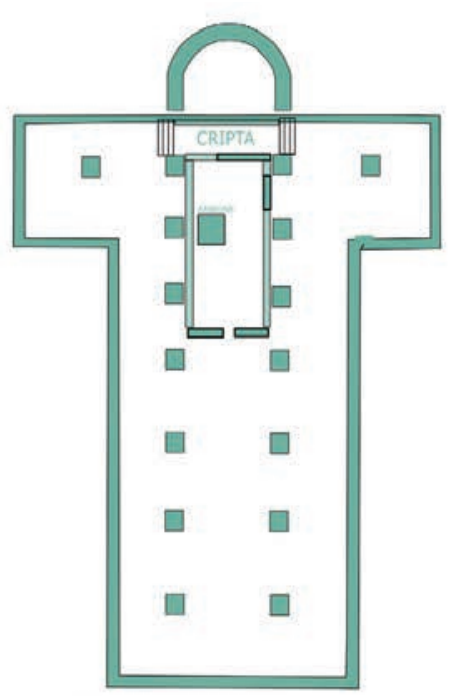

SS. Giovanni e Reparata (Lucca)

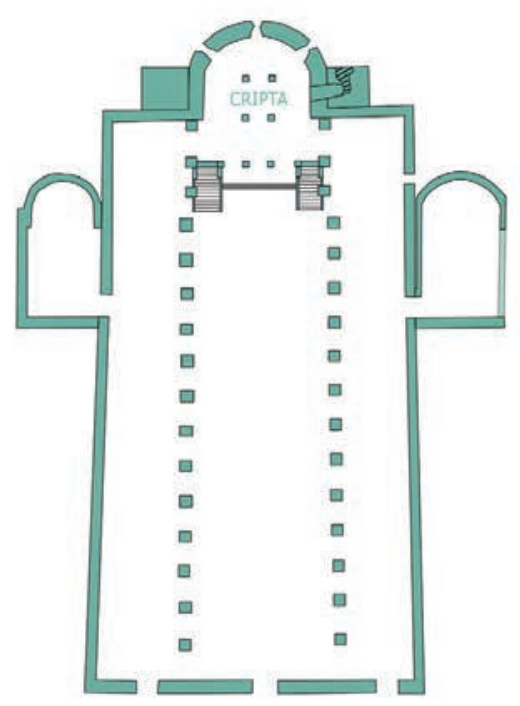

S. Reparata (Firenze)

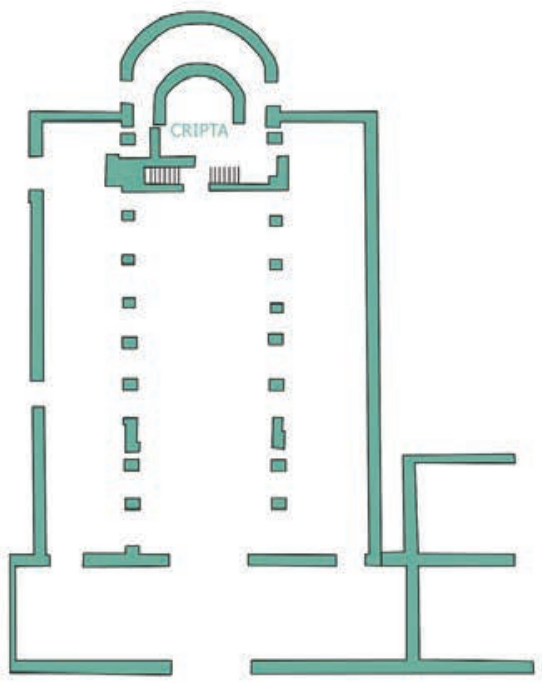

S. Maria (Luni)

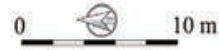

Fig. 5: principali interventi nell ecclesiae episcopales in età caroloingia: si noti, in particolare, l'inserimento delle cripte (elaboraz. a.).

direttamente dal dux d'istanza a Lucca, Allone ${ }^{70}$ ) e anche di strutture assistenziali come gli xenodochia che, talvolta, risultarono associati agli stessi monasteria: è ad esempio il caso di San Silvestro in Placule, sorto nel suburbium meridionale di Lucca, fondato nel 720 e dotato di un sinedoco vel balneo cum fundamentis vel ortas ${ }^{71}$. Uno dei casi più significativi, soprattutto per comprendere le tipologie strutturali di queste fondazioni di VIII secolo, è determinato indubbiamente dal caso di San Ponziano, posto nel suburbio orientale e indagato stratigraficamente abbastanza di recente: attestato per la prima volta agli inizi del IX seco$\mathrm{lo}^{72}$, esso si caratterizza per un'icnografia molto semplice, dispiegandosi in un'aula absidata a navata unica, estesa per circa sessanta metri quadrati, che ha restituito una prima fase databile appunto al secolo VIII73. La tecnica costruttiva vede il fitto impiego di ciottoli di fiume disposti a "spina di pesce", secondo un'apparecchiatura muraria che sia in ambito urbano (su tutti, le fasi altomedievali della chiesa dei Santi Giovanni e Reparata) che in quello rurale, come a San Giusto alla Caipira o a San Martino in Ducentola, trova confronti puntualissimi, che rendono tale organizzazione dei setti murari un vero e proprio fossile guida per l'VIII ed il IX secolo lucchese (fig. 4).
Fenomeni analoghi si verificano anche nella vicina Pistoia, ove in età longobarda vengono istituiti monasteri urbani e suburbani, anche qui, in alcuni casi, per emanazione del potere temporale, come il monastero $S$. Bartholomei foras muro civitatis Pistoriensis, fatto edificare da Gaidoaldo, medicus regie potestatis ${ }^{74}$, promotore anche di un altro complesso monastico suburbano ${ }^{75}$, di cui disponiamo di una significativa descrizione di parte delle strutture, in particolar modo di una sala pedeplana, mura cercumdata, scandula coperta, associata ad un orto e ad un molino ${ }^{76}$.

Durante l'età carolingia, invece, il numero delle nuove fondazioni urbane venne decisamente meno (si rimanda ancora al grafico in fig. 2), ma, ciononostante, le politiche di intervento nell'ambito dell'edilizia ecclesiastica sembrarono comunque avere un filo conduttore ben evidente, anche dal semplice punto di vista tipologico. Innanzitutto, si registrano importanti interventi di restauro e monumentalizzazione in tutte le principali ecclesiae episcopales: sia a Firenze ${ }^{77}$, che a Lucca ${ }^{78}$ che a Luni ${ }^{79}$ le chiese vescovili vennero dotate di grandi cripte (fig. 5), secondo risoluzioni da riconnettere molto probabilmente al nuovo impulso dato al culto dei santi proprio in età franca ${ }^{80}$, una devozione che, evidentemente, aveva nelle cripte il principale vettore materiale della ritualità

\footnotetext{
$\overline{7^{70} \text { quod Allo dux aedificavit (M.G.H., Diplomatum Karolinorum, III, p. } 266}=$ TH. Schieffer (a cura di), in Monumenta Germaniae Historica, Diplomatum Karolinorum, III, Lotharii I et Lotharii II diplomata, Berlin, 1966).

${ }^{71} C D L$, I, n. 24.

${ }^{72}$ Nell'833 d.C. (MD/V, n. 867).

${ }_{73}$ G. CIAMPOLTRINI, Il contributo dell'archeologia alla definizione del contesto urbano medievale lucchese, in C. Bozzoli, M.T. Filieri (a cura di), Scoperta Armonia: Arte Medievale a Lucca, Lucca, 2014, p. 35-59.

${ }^{74} R C P$, n. 7, del 743 d.C. (RCP = N. RaUty (a cura di), Regesta chartarum Pistoriensium. Alto Medioevo (493-10oo), Pistoia, 1973).

${ }_{75}$ Situato a partibus orientali usque in flubio Braina (CDL, I, n. 38 del 726$)$.

${ }^{76} \mathrm{CDL}, \mathrm{I}, \mathrm{n} .38$.

77 F. TOKER 1975, op. cit. (n. 33); F. TOKER 2013, op. cit. (n. 33).

${ }^{78}$ L. PANI ERMINI, op. cit. (n. 30 ).

${ }^{79}$ LUSUARDI SIENA, op. cit. (n. 44).

${ }^{80}$ Su questo aspetto di veda P. FOURACRE, The origins of the Carolingian attempt to regulate the cult of the Saints, in J.D. Howard-Johnston, P.A. Hayward (a cura di), The Cult of Saints in Late Antiquity and the Middle Ages. Essays on the Contribution of Peter Brown, Oxford, 2002, p. 143-165.
} 


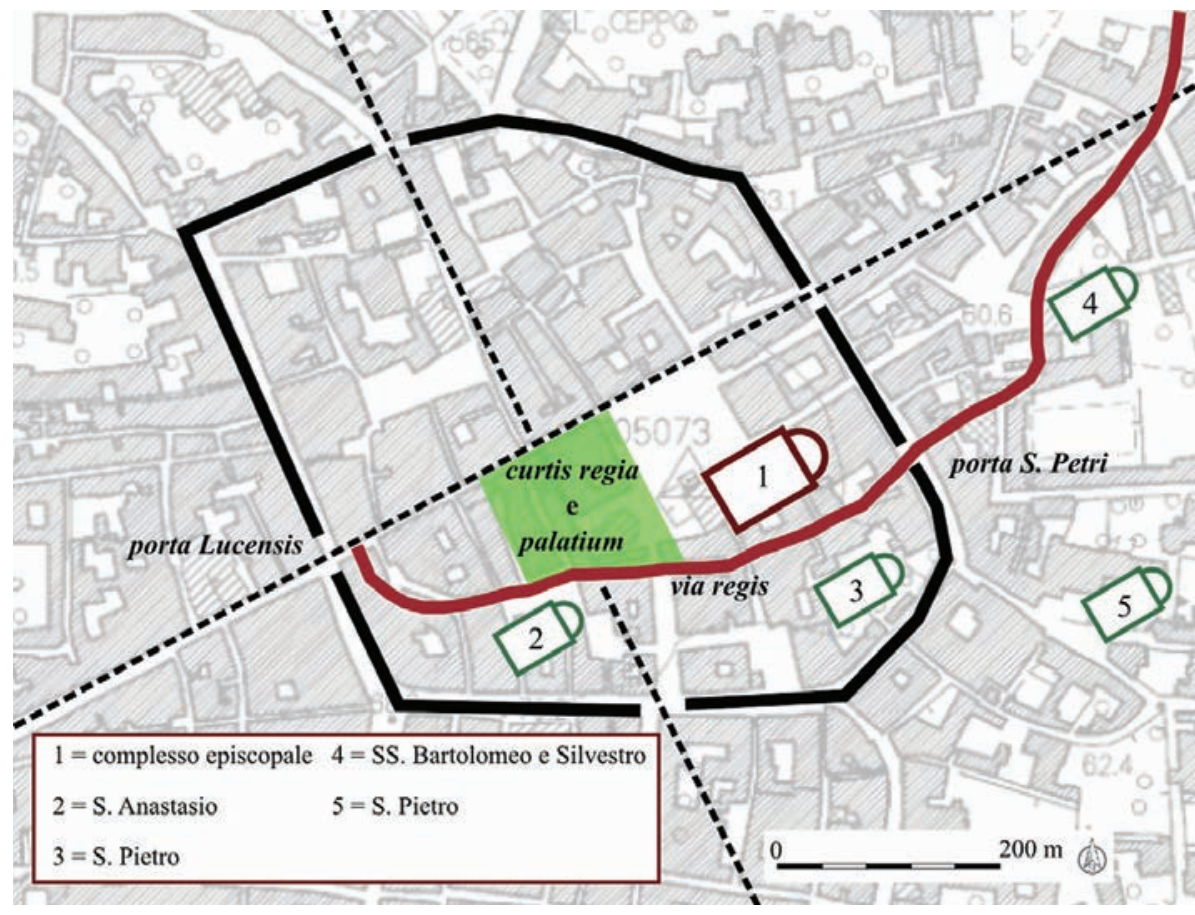

Fig. 6: asseti topografici della Pistoia altomedievale, con la via regis perno dell'urbanesimo e dei principali poli edilizi (elaboraz. a.).

e della prassi liturgica legata alla venerazione dei martiri. Nel IX secolo, inoltre, si attesta ampiamente un modello edilizio destinato a divenire caratterizzante dell'edilizia religiosa di età carolingia ${ }^{81}$, ovverosia quello di chiese con lunghe aule terminanti con aree presbiteriali caratterizzate da tre absidi (quasi a forma di " $\mathrm{T}$ ") - come nel caso della cosiddetta 'Badia fiorentina', a Firenze ${ }^{82} \mathrm{o}$, in contesto rurale, la fase di IX-X secolo di Santa Maria a Monte in provincia di $\mathrm{Pisa}^{8_{3}}$ - o quello dei triconchi, come nella Santa Trinità di Firenze ${ }^{84}$ (si veda la fig. 10, nelle conclusioni).

Se, dunque, le politiche dell'edilizia religiosa registrabili nella Tuscia franca risultarono in forte calo dal punto di vista quantitativo (nelle città, perché, comevedremo, nei contesti rurali il panorama fu ben differente), il IX secolo, però, sembrerebbe al contempo connotare un intento programmatico non più volto alla sovraesposizione e saturazione edificatoria tipiche dei secoli longobardi ma, piuttosto, ad una volontà di interventi edilizi mirati, finalizzati a migliorare e potenziare l'apparato monumentale già esistente, ma anche ad arricchirlo con nuovi impulsi architettonici. Non solo, l'età carolingia sembra anche potersi configurare come il 'termine ultimo' della rivoluzione topografica iniziata in età tardo antica, che vide nel ribilanciamento degli assetti urbani tipici della civitas classica e nella commistione topografica tra edifici ecclesiali e strutture del potere temporale il proprio zenit.

In tal senso, risulta emblematico il caso di Pistoia, ove i principali luoghi di culto cristiano noti nell'alto medioevo longobardo e franco si andarono a disporre lungo il nuovo percorso determinato dalla via regis ${ }^{85}$, asse viario posto nella parte centro meridionale della città, sulla cui assialità dovettero insistere anche i grandi spazi del potere politico, come il palatium ${ }^{86} \mathrm{e}$ la curtis dominis regi ${ }^{87}$ (fig. 6): tale fenomeno è del resto emblematico di quanto, in tempi recenti, ha ben messo in luce anche Hendrik Dey, ovverosia dell'importanza assunta dalle vie 'monumentali' nelle città post classiche, che si dispiegano non solo come apparati di ordine funzionale, ma anche come veicoli di ostentazione ed autorappresentazione del potere in ogni sua forma, in una sorta di legame ideale con quelli che erano già stati i percorsi del cerimoniale e dell'adventus tardo antichi ${ }^{88}$.

\section{LE CAMPAGNE: DALLE FORMAZIONE DELLA RETE ECCLESIASTICA ALLA STRUTTURAZIONE DEL SISTEMA PIEVANO.}

Anche in questo caso, non ci si soffermerà in maniera approfondita sui mutamenti delle campagne dal punto di vista economico ed insediativo nei secoli tardo antichi ed altomedievali, dal momento che la bibliografia risulta forse ancora più ricca che per le città ${ }^{89}$, ma, piuttosto, ne verranno tratteggiati solamente i fenomeni caratterizzanti,

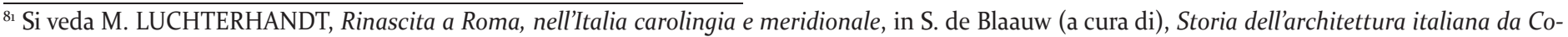
stantino a Carlo Magno, II voll., Milano, 2010, p. 322-373.

${ }^{82}$ Si vedano K. UETZ, La chiesa invisibile: riscoperta della medievale Badia fiorentina, in Bollettino degli Ingegneri, 11, 2004, pp. 3-12 e K. UETZ, La Badia di Firenze. Die Abteikirche von Florenz. 969-1310, Bamberg, 2006.

${ }^{8}$ F. REDI, La Rocca di Santa Maria a Monte (Pisa). Saggi preliminari e programma di ricerca, in Archeologia medievale, 14, 1987, pp. 319-327; F. REDI, S. Maria a Monte (PI): una chiesa, un castello, una pieve, una canonica nella media valle dell'Arno. Documenti ed evidenze archeologiche a confronto, in S. Campana, C. Felici, R. Francovich, F. Gabbrielli, op. cit. (n. 2), p. 224-243.

${ }^{84}$ H. SAALMAN, Florence: Santa Trinità I and II, and the 'Crypts' under Santa Reparata and San Pier Scheraggio, in Journal of the society of architectural historians, 21, 1962, p. 179-187; H. SAALMAN, The church of Santa Trinita in Florence, Pittsburg, 1966.

${ }^{8} 998$ d.C. $(R C P$, n. 105).

${ }^{86} 812$ d.C. $(R C P$, n. 30$)$.

${ }^{87} 806$ d.C. $(R C P$, n. 26$)$.

${ }^{88}$ H.W. DEY, The Afterlife of the Roman City, New York, 2015, in particolare l'ampio capitolo alle p. 65-126.

${ }^{89}$ Senza pretesa di esaustività bibliografica si vedano (ivi bibl.): M. VALENTI, op. cit. (n. 6); M. VALENTI, op. cit. (n. 15); M. VALENTI, La Toscana prima e dopo il 774. I segni delle aristocrazie in ambito urbano e rurale, in S. Gasparri (a cura di), 774. Ipotesi su una transizione, Atti del seminario di Poggibonsi, 16-18 febbraio 2006, Turnhout, 2008, p. 221-261; M. VALENTI, La Toscana rurale del V secolo, in P. Delogu, S. Gasparri (a cura di), op. cit. (n. 16), p. 501535; F. CANTINI, Dall'economia complessa al complesso di economie. Tuscia (V-X secolo), in Post Classical Archaeologies, 1, 2010, p. 154-194; F. CANTINI, La Tuscia settentrionale tra IV e VII secolo: nuovi dati archeologici sulla transizione, in C. Ebanista, M. Rotili (a cura di), La trasformazione del mondo romano e le grandi migrazioni. Nuovi popoli dall'Europa settentrionale e centro-orientale alle coste del Mediterraneo, Atti del Convegno internazionale di studi (Cimitile-Santa Maria Capua Vetere, 16-17 giugno 2011), Cimitile, 2012, p. 163-175; F. CANTINI, Aree rurali e centri urbani tra IV e VII secolo. Il territorio toscano, in Antiquité tardive, 21, 2013, p. 243-255; G. BIANCHI, Recenti ricerche nelle Colline Metallifere ed alcune riflessioni sul modello toscano, in Archeologia medievale, 52, 2016, p. 9-26.
} 
fondamentali per comprendere le evoluzioni della rete ecclesiastica nei contesti rurali fino al X secolo circa.

È già stato evidenziato come la suddivisione della Tuscia in Annonaria e Suburbicaria occorsa in età tardo romana non sia stata solo un aspetto puramente politico, ma come abbia avuto, in effetti, ricadute anche dal punto di vista economico ed insediativo. Tale aspetto è ben tracciabile nelle realtà urbane ${ }^{90}$, ma è ben visibile anche negli assetti rurali, al punto che ormai, già da alcuni anni, non è infrequente sentir parlare di una "Toscana a due velocità" 91. Come è stato infatti anche recentemente evidenziato, la zona posta grossomodo a Sud del bacino del fiume Arno vide una contrazione ed un abbandono dei siti rurali, in primis le ville, già a partire dalla seconda metà del III secolo, con rioccupazioni di scarsa entità occorse nel IV e nel V secolo, prevalentemente a destinazione artigianale ${ }^{92}$ (nel grossetano, nel medesimo arco cronologico, ben il 59\% dei siti sembra svanire ${ }^{93}$ ). Nella parte settentrionale della Tuscia, invece, in fasi contemporanee si attestano importanti investimenti strutturali nelle ville, come ad esempio nel caso di San Vincenzino presso Cecina (Li), ove nel IV secolo si documentano consistenti rifacimenti sia della zona residenziale che degli impianti produttivi ${ }^{94}$ e dove è stata ipotizzata - sebbene con prudenza - la presenza di membri legati all'aristocrazia addirittura fino al VI secolo ${ }^{95}$, o nella villa dei Vanulei a Massaciuccoli (Lu) ${ }^{96}$; nella Villa dell'Oratorio a Capraia e Limite (Fi), nel corso del IV secolo alcune aree vengono ristrutturate, con l'inserimento di vani absidati dotati di pregevoli tappeti musivi ${ }^{97}$, connotandola come un contesto di straordinaria importanza dal momento che, come attesta un rinvenimento epigrafico, è altamente probabile che per un certo periodo fosse stata di proprietà del celebre Vettio Agorio Pretestato, corrector Tusciae et Umbriae prima del 362 d.C., nonché prafectus Urbi dal 368 al 384 d.C., la cui presenza in Tuscia è menzionata anche nelle epistuale di Quinto Aurelio Simmaco ${ }^{98}$.

In che modo, dunque, si andò a configurare la rete ecclesiastica in questo panorama insediativo? Per il periodo compreso tra il IV ed il VII secolo, invero, in ambito rurale, il dato quantitativo (comprensivo di contesti indagati archeologicamente e noti dalle fonti) è estremamente povero, soprattutto se confrontato al totale degli edifici schedati, attestandosi all'1,8\% del totale: si tratta, evidentemente, dal punto di vista statistico, di un valore molto ridotto che, però, molto probabilmente dipende in parte da quella - più volte evocata - carenza di progettualità e conseguente mancanza di indagini stratigrafiche sul lungo periodo che ha caratterizzato la ricerca sugli edifici di culto cristiano in Toscana e, in parte, da un assordante silenzio delle fonti scritte per questo arco cronologico, pesantemente sperequato rispetto a quanto avviene dall'VIII secolo in poi (vedi supra). Bisogna inoltre sottolineare come quasi sempre, come vedremo adesso, nei casi in cui siano state effettuate campagne di scavo intensive su contesti ecclesiastici attestati solamente dall'VIII-IX secolo, si sia giunti a mettere in luce anche la facies tardo antica degli edifici, un aspetto che, pertanto, ci deve mettere in guardia dal tratteggiare panorami eccessivamente desolanti per quanto concerne la rete ecclesiastica rurale di epoca tardo antica. Uno dei casi più eccezionali è, indubbiamente, quello di San Piero a Grado, nei pressi di Pisa: il contesto sorge in un bacino topografico che, in età romana, corrispondeva all'incirca al passaggio della linea di costa antica, attualmente più avanzata, e doveva insistere a breve distanza da un importante scalo portuale ${ }^{99}$.

\footnotetext{
9o Si rimanda a F. CANTINI, C. CITTER, op. cit. (n. 16), (ivi bibl.).

${ }^{91}$ Sulle 'due Toscane' si veda F. CAMBI, Cosa e Populonia. La fine dell'esperienza urbana in Etruria e la nascita delle due Toscane, in Workshop di Archeologia Classica, 2, 2005, p. 71-90.

${ }_{92}^{2}$ Si vedano M. VALENTI, op. cit. (n. 15), VALENTI, op. cit. (n. 89), CANTINI, op. cit. (n. 89), in particolare a p. 248. Per l'inserimento di attività artigianali negli spazi precedentemente occupati da villae e mansiones/stationes, significativi esempi nel territorio toscano si hanno dalla villa di Aiano/Torraccia di Chiusi, presso San Gimignano (per una sintesi sul contesto di veda M. CAVALIERI, Quid igitur est ista villa? L'Etruria centro-settentrionale in tarda Antichità e alto Medioevo. Nuovi dati e vecchi modelli a confronto sulla villa di Aiano-Torraccia di Chiusi (Siena, Italia), in G. Schörner (a cura di), Atti del Convegno Internazionale "Leben auf dem Lande: Der Fundplatz. 'Il Monte' bei San Gimignano: Eine römische Siedlung und ihr Kontext” (Jena, 19-21 Juni 2009), Wien, 2013, p. 83-319) e dal vicus/mansio di Santa Cristina in Caio, presso Buonconvento (SI) (S. BERTOLDI, M. VALENTI, Santa Cristina in Caio a Buonconvento (Siena): un bilancio interpretativo dopo la sesta campagna di scavo, in The Journal of Fasti Online, 2015, www.fastionline.org/docs/FOLDER-it-2015-338. pdf). Inoltre, per un bilancio a livello nazionale su abbandoni e rioccupazioni dei siti rurali si vedano A. CASTRORAO BARBA, Continuità topografica in discontinuità funzionale: trasformazioni e riusi delle ville romane in Italia tra III e VIII secolo, in Post-Classical Archaeologies, 4, 2014, pp. 259-296 (ivi bibl.) e A. CASTRORAO BARBA, Le ville romane in Italia tra III e VI sec. $d$ C.: approccio statistico e considerazioni generali, in Amoenitas. Rivista internazionale di studi miscellanei sulla Villa Romana antica, 3, 2014, p. 9-24.

${ }^{93}$ E. VACCARO, Sites and Pots: Settlement and Economy in Southern Tuscany (AD 300-90o), Oxford, 2011, p. 20.

${ }^{94} \mathrm{~F}$. DONATI, La villa romana dei Cecina a San Vincenzino (Livorno). Materiali dello scavo e aggiornamenti sulle ricerche, Ghezzano (Pi), 2013, p. 154-155 e alle p. 329-345 per la realizzazione di un grande quartiere di rappresentanza, con coenatio, realizzato nel pieno IV secolo d.C.

${ }^{95}$ F. Donati, op. cit. (n. 94), p. 156, in cui l'a. discutendo la fase di fine V-metà VI secolo d.C. della villa, afferma che "I materiali associati, tra cui molteplici importazioni dall'Africa, ci attestano come a installazioni relativamente modeste - o comunque meno leggibili dal punto di vista archeologico - possano corrispondere importazioni di merci pregiate che ci documentano un tenore di vita non infimo in presenza forse di un ceto ancora aristocratico".

${ }^{96}$ G. CIAMPOLTRINI, La "villa" di Massaciuccoli. Una proposta di lettura, in Rassegna di archeologia, 15, 1998, p. 107-11. Per la fine della villa e le frequentazioni post-classiche, sino ad epoca rinascimentale, si veda G. CIAMPOLTRINI, P. NOTINI, Massaciuccoli (Com. Massarosa, Lucca): ricerche sull'insediamento post-classico nella villa romana, in Archeologia medievale, 20, 1993, p. 393-407.

${ }^{97}$ L. ALDERIGHI, F. CANTINI, Capraia e Limite. La villa dei Vetti: nuove e vecchie indagini archeologiche, in Notiziario della Soprintendenza per $i$ beni archeologici della Toscana, 6, 2011, p. 47-81; F. CANTINI, op. cit. (n. 89), p. 166-167; L. ALDERIGHI, F. CANTINI, B. FATIGHENTI, Capraia e Limite (FI). Nuovi dati dalla villa dell'Oratorio, in Notiziario della Soprintendenza per i beni archeologici della Toscana, 9, 2014, p. 295-296.

${ }_{98}^{8}$ SYMMACHUS, Ep., I-51 = O. Seeck (a cura di), in Monumenta Germaniae Historica, Q. Aurelii Symmachi quae supersunt, Berolini, 1883; su questi aspetti, in generale, si vedano anche M. KAHLOS, Vettio Agorio Pretestato. Una vita senatoriale nella transizione, Forli, 2010, p. 30-31 e L. ALDERIGHI, F. CANTINI, op. cit. (n. 97), p. 54

${ }^{99}$ Si vedano F. REDI, La basilica di S. Piero a Grado, in Terre e paduli: reperti, documenti, immagini per la storia di Coltano, Pontedera, 1986, p. 216-228; F. REDI, Le strutture edilizie della basilica di S. Piero a Grado dalle origini al sec. XV, in M. L. Ceccarelli Lemut, S. Sodi (a cura di), Nel segno di Pietro. La basilica di S. Piero a Grado da luogo della prima evangelizzazione a meta di pellegrinaggio medievale, Pisa, 2003, p. 99-116; F. REDI, Cristianizzazione e
} 


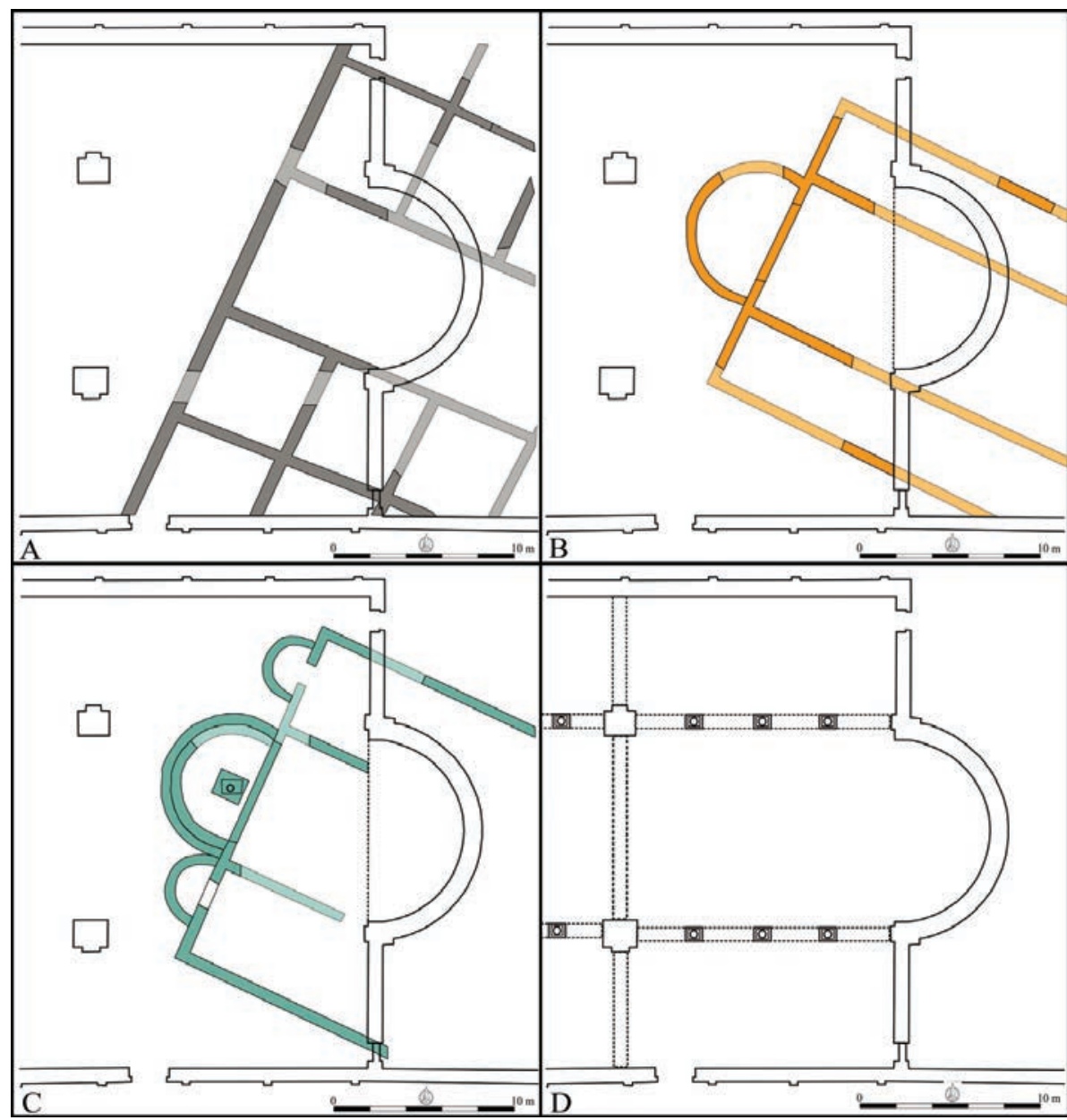

Fig. 7: San Piero a Grado: A) In grigio le murature di età imperiale B) Le strutture pertinenti alla prima fase della chiesa, di fine IV-inizi $V$ secolo $d . C$. C) i rifacimenti della chiesa in età altomedievale

(VIII-IX sec. d.C.) D) planimetria di parte dell'edificio pre-romanico, posto ad obliterare le fasi antecedenti (elaboraz. a.).

In quest'area, in una non meglio precisata età imperiale, vennero edificate una serie di strutture, caratterizzate da almeno dodici ambienti quadrangolari, interpretate da alcuni come ambienti residenziali ${ }^{100}$, da altri come infrastrutture portuali ${ }^{101}$. In un momento inquadrabile agli inizi del $\mathrm{V}$ secolo, parte di questi vani fu riconvertita per la messa in opera di una grande basilica cristiana: in particolar modo, due murature parallele andarono a tagliare parte di quelle precedenti, onde mettere in opera i perimetrali della chiesa, che riutilizzò, per la navata centrale, l'ingombro di un lungo vano rettangolare, pertinente alla fase di età imperiale $^{102}$ (fig. 7). Un aspetto estremamente importante per la comprensione del rapporto tra l'edificio più antico e la basilica è inoltre dettato dal fatto che i seppur mal preservati lacerti di pavimentazione superstiti di quest'ultima sembrerebbero impostarsi direttamente al di sopra dei piani d'uso dei vani residenziali: ne consegue che, dunque, perlomeno in questo bacino stratigrafico, la chiesa andò indubbiamente a riconvertire la destinazione funzionale di una preesistenza, ma al contempo non sembrerebbero sussistere evidenze stratigrafiche chiare che possano darci informazioni univoche sul fatto se il contesto insediativo in cui la basilica sorse fosse ancora parzialmente attivo o meno.

Indubbiamente, però, San Piero a Grado si caratterizzò fin da subito come un edificio assolutamente straordinario per un contesto extra urbem, definendosi, con le sue tre navate e notevoli dimensioni (circa $20 \times 35 \mathrm{~m}$ ), come una costruzione affine - per tipologia, monumentalità ed impatto - alle grandi ecclesiae episcopales urbane: tale aspetto, del resto, non stupisce, dal momento che San Piero a Grado sorse in relazione al luogo in cui, secondo un тótos agiografico (ed evidentemente del tutto inattendibile dal punto di vista della veridicità storica), sarebbe sbarcato San Pietro per evangelizzare Pisa ed il suo territorio ${ }^{103}$, una credenza che, evidentemente, ingenerò una devozione che ben presto si radicò fortemente nell'areale pisano, al punto che l'edificio ebbe importanti opere di restauro e potenziamento anche nel corso dell'alto medioevo (quando era meta di numerosi pellegrinaggi) ${ }^{104}$, sino al suo grande rifacimento occorso nell'avanzato X secolo ${ }^{105}$.

Un altro contesto di notevole importanza nella Tuscia rurale è rappresentato senza dubbio da Sant'Ippolito di Anniano, presso Santa Maria a Monte (Pi): negli immediati pressi del corso del fiume Arno, in una zona già densamente frequentata in epoca etrusca, indagini di scavo condotte nel 1999-2000 hanno consentito di portare in luce un contesto pluristratificato, che vide le proprie origini in età augusteo-tiberiana. A questa prima fase sono da ascrivere due strutture pertinenti ad un contesto rurale a vocazione produttiva, trattandosi di un calcatorium e di un lacus ${ }^{106}$,

insediamenti ecclesiastici alla foce dell'Arno fra V e XI secolo, in M. Rotili (a cura di), Tardo antico e alto medioevo. Filologia, Storia, Archeologia e Arte, Napoli, 2009, p. 87-102.

${ }^{100}$ F. REDI, op. cit. (n. 99), pp. 88-89: l'a. le definisce come pertinenti ad una domus, ma trovandoci in contesto non urbano, non si può escludere che in realtà siano da attribuire ad una villa, forse legata all'approdo sulla costa.

${ }^{101}$ P. SANPAOLESI, op. cit. (n. 36), p. 66; S. BRUNI, L'area di San Piero a Grado prima della costruzione della basilica. Ipotesi in forma di appunti sui dati archeologici, in M. L. Ceccarelli Lemut, S. Sodi (a cura di), op. cit. (n. 99), pp. 81-98.

${ }^{102}$ F. REDI 2009, op. cit. (n. 99), pp. 89-90.

${ }^{103}$ Sulla quaestio agiografica si vedano F. POLESE, S. Piero a Grado e la sua leggenda, Livorno, 1905; N. TOSCANELLI, Lo sbarco di S. Pietro a Pisa, Livorno, 1930; M.L. CECCARELLI LEMUT, S. Piero a Grado e il culto petrino nella diocesi di Pisa, in M. L. Ceccarelli Lemut, S. Sodi (a cura di), op. cit. (n. 99), pp. 19-26; S. SODI, S. Piero a Grado e la via marittima dell'evangelizzazione della Tuscia costiera, in M. L. Ceccarelli Lemut, S. Sodi (a cura di), op. cit. (n. 99), p. 11-18.

${ }^{104}$ M.L. CECCARELLI LEMUT, op. cit. (n. 103).

${ }^{105}$ F. REDI, op. cit. (n. 99), pp. 97-98.

${ }^{106}$ G. CIAMPOLTRINI, R. MANFREDINI, La pieve di Sant'Ippolito di Anniano a Santa Maria a Monte. Scavi 1999-200o, in Archeologia medievale, 28, 2001, p. 163-184; G. Ciampoltrini, R. Manfredini (a cura di), Sant'Ippolito di Anniano a Santa Maria a Monte. Preistoria e storia di una pieve sull'Arno, Pontedera, 2005, p. 12. 


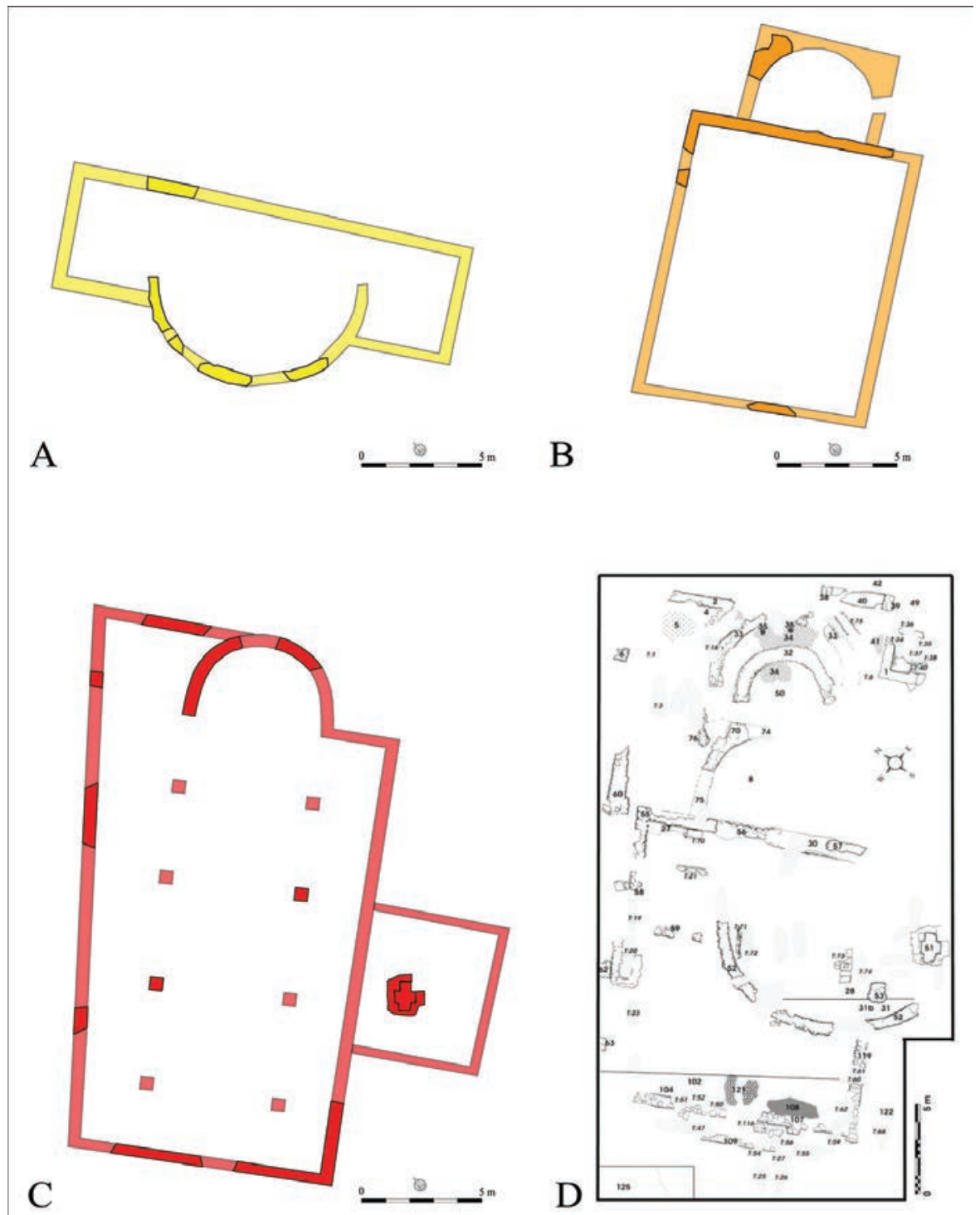

Fig. 8: Sant'Ippolito d'Anniano: A) la struttura di IV secolo, interpretata come martyrium o mausoleo B) La prima fase della chiesa, di fine IV-inizi $V$ secolo d.C. C) l'ampliamento della chiesa in età altomedievale, con l'aggiunta del fons baptismalis D) Planimetria complessiva dello scavo (elaboraz. a., ad eccezione di D, da G. CIAMPOLTRINI, R. MANFREDINI 2005).

probabilmente in uso fino ad epoca tetrarchia o, al massimo, alla prima età costantiniana ${ }^{107}$ : all'incirca alla metà del IV secolo, sui resti delle strutture precedenti venne impiantato un edificio, mal preservato, caratterizzato da un' esedra e da un ampio vano - invero in gran parte ipotetico - interpretato dagli scavatori come sorta di martyrium e, dunque, già caratterizzato da una valenza cristiana, oppure come mausoleo ancora pagano ${ }^{108}$, lasciando, dunque, l'interpretazione giustamente 'aperta', considerati gli scarsi indicatori restituiti dal deposito archeologico (fig. 8).

Agli inizi del V secolo il complesso subì una completa e significativa riconfigurazione $^{109}$ : la facies del 'martyrium-mausoleo' venne obliterata da un nuovo edificio ad aula basilicale, con abside esternamente rettangolare ed internamente semicircolare, stavolta più chiaramente caratterizzabile come chiesa, anche per parziali analogie strutturali con il San Frediano lucchese ${ }^{110}$ (fig. 8). Sebbene in questo caso (come invero nella maggior parte) risulti molto complesso, per non dire quasi impossibile, risalire con precisione alla figura del fondatore del complesso, è interessante rilevare, con G. Ciampoltrini e R. Manfredini, come nelle stesse fasi in cui nella villa dell'Oratorio forse risiedeva Vettio Agorio Pretestato, forte propugnatore del paganesimo, a Sant'Ippolito di Anniano, "per iniziativa di un dominus cristiano, o per autonoma impresa della comunità cristiana locale, si innalzava un edificio destinato a favorire la diffusione della nuova religione nelle campagne" (vedi supra).

Un ultimo contesto di notevole interesse per la configurazione delle campagne tardo antiche e la loro progressiva caratterizzazione con un edilizia cristiana è rappresentato da San Pietro in Campo a Montecarlo, in provincia di Lucca: in questo caso siamo di fronte ad un edificio di culto la cui prima attestazione rimanda all'847, anno in cui viene menzionata come sita in loco Piscia magiore quot est pleve batismale ${ }^{111}$. I dati a disposizione per ricostruire il contesto insediativo in cui sorse il complesso cristiano sono, stavolta, molto precari: le indagini condotte nel 2006 all'interno della Parrochia di San

\footnotetext{
${ }^{107}$ G. Ciampoltrini, R. Manfredini (a cura di), op. cit. (n. 106), p. 30.

${ }^{108}$ Ibidem, pp. 30-31.
}

${ }^{109}$ Secondo gli studiosi del contesto, la seconda fase sarebbe più precoce, attribuendola al tardo IV secolo d.C., in base alla presenza di reperti numismatici pertinenti a cronologie che si attestano, nelle emissioni più tarde, agli anni di Giuliano l'Apostata (G. Ciampoltrini, R. Manfredini (a cura di), op. cit. (n. 106), pp. 27-28). Bisogna però rimarcare come, ovviamente, gli anni 361-363 d.C. siano da leggere come terminus post quem e, soprattutto, come i livelli da cui provengono le monete (USS 8 e 102) sembrino, nella descrizione della sequenza stratigrafica, successivi alla realizzazione delle murature di fase II: "Alla struttura 55, con una cesura dovuta alla spoliazione del tratto occidentale del tessuto murario (75), si innestava l'ambiente quadrangolare all'esterno, curvilineo all'interno, costruito con la stessa tecnica, e ugualmente immerso in un livellamento coerente nella sua eterogeneità, esito della ripetuta realizzazione di focolari, verosimilmente all'aperto o appena protetti, sul suolo sabbioso-limoso che veniva progressivamente innalzato. Variamente denominato (8 e 50 nell'area orientale dello scavo, all'interno della struttura 70; 102 nell'area occidentale, con la vasta lente di concotto 108), il livello con focolari, lenti carboniose o di ceneri che si dispone sul suolo sabbioso, di base, come nel settore orientale, o esito dei livellamenti collegati alla costruzione di Sant'Ippolito I, affiorava per vasti tratti dello scavo appena rimosso il terreno agricolo, e consente dunque di raccordare alle strutture 70-55+58-57, l'isolato lembo murario 109, costruito con identica tecnica, e ugualmente 'immerso' nello strato 102" (G. Ciampoltrini, R. Manfredini (a cura di), op. cit. (n. 106), p. 25). Inoltre, la presenza di un vaso a listello in sigillata africana da US 106 - anch'essa da eguagliare, sostanzialmente, a US 102 (G. Ciampoltrini, R. Manfredini (a cura di), op. cit. (n. 106), p. 31, fig. 29-3) e, dunque, ad un'azione di livellamento su cui si impostarono le murature della seconda fase - sembrerebbe rimandare agli inizi del V secolo d.C. piuttosto che alla fine del IV (a tal proposito si vedano J.W. HAYES, Late Roman Pottery, Roma, 1972, p. 140-144 e M. BONIFAY, Etudes sur la céramique romaine tardive d'Afrique, Oxford, 2004, p. 177-181).

${ }^{110} \mathrm{G}$. CIAMPOLTRINI, P. NOTINI, op. cit. (n. 53).

${ }^{\mathrm{m}} \mathrm{MD} / \mathrm{V}, \mathrm{n} .1148$. 


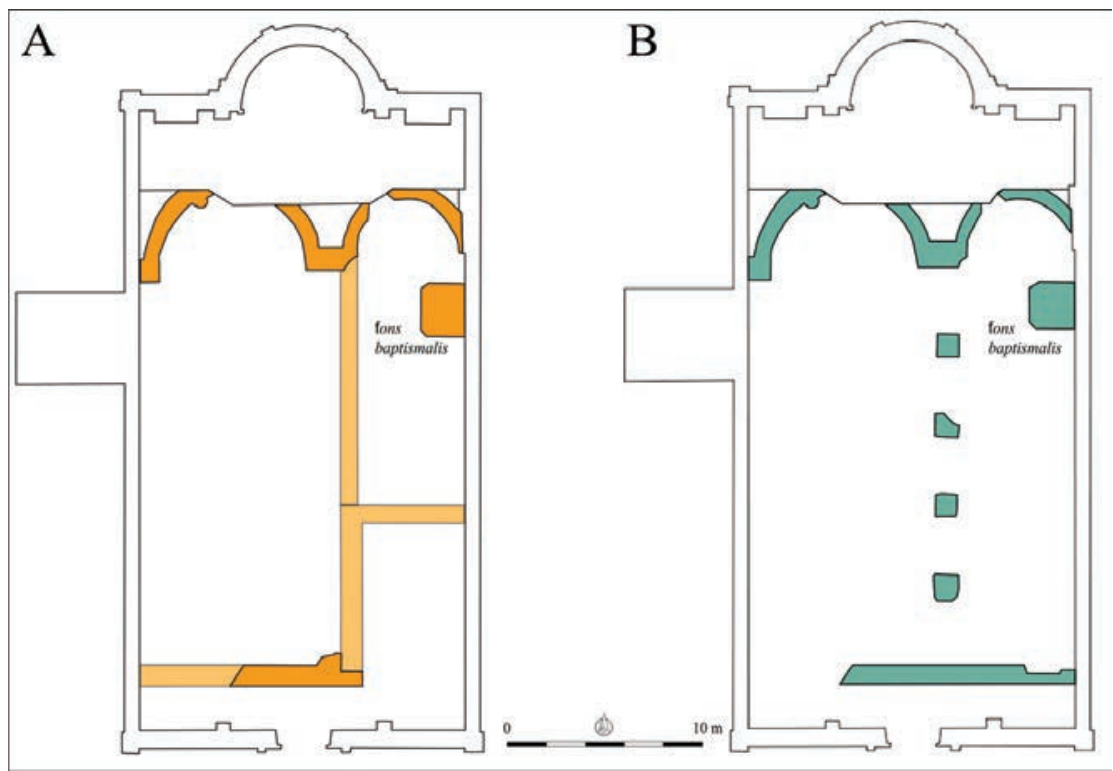

Fig. 9: San Piero in Campo: A) la fase tardo antica B) le modifiche di età altomedievale, con la congiunzione dell'aula e del battistero (elaboraz. a.)

Pietro Apostolo, infatti, hanno consentito esclusivamente di verificare come la prima fase dell'edificio di culto fosse sorta su una serie di livellamenti caratterizzati da materiali ceramici volti a definire un terminus post quem di metà IV secolo ${ }^{112}$, dato preziosissimo dal punto di vista cronologico, ma molto meno da quello topografico, non permettendoci di comprendere l'entità complessiva delle eventuali preesistenze. La prima fase della chiesa è caratterizzata da due aule giustapposte, entrambe absidate, di cui quella posta a nord rappresenta l'ecclesia vera e propria, mentre quella a meridione, di dimensioni ridotte, era destinata ad accogliere un fons baptismalis ${ }^{13}$ (fig. 9), denunciando una funzione di cura animarum di San Pietro in Campo già dal primo impianto, la cui datazione puntuale, però, risulta in parte problematica. Infatti, Giulio Ciampoltrini, a fronte di una carenza di materiali pienamente affidabili per poter definire un ambito cronologico preciso di fondazione della chiesa e, dunque, basandosi prevalentemente su confronti nel territorio, propone giustamente una cronologia 'ampia', oscillante a fine IV-inizi V secolo ${ }^{114}$ che, sfortunatamente, non sembra poter essere ulteriormente affinabile e circoscrivibile.

Un contesto destinato a divenire uno dei siti rurali di maggior importanza nell'ambito delle dinamiche di popo- lamento e cristianizzazione di tutta la Tuscia settentrionale nel pieno alto medioevo, ossia il vicus Wallari, presso San Genesio (Pi), in queste fasi è, invece, ancora privo di evidenze legate all'inserimento di una materialità dell'edilizia religiosa, denunciando la consistenza di emergenze che lo tratteggiano fino all'avanzato IV secolo come probabile mansio, ove nel V-VI secolo verrà inserita una necropoli, cui si associa anche un probabile mausoleo, conservato però solo in fondazione ${ }^{115}$.

Dalla sintetica descrizione di questi siti "chiave" per la disamina delle prime testimonianze monumentali del cristianesimo nelle campagne della Tuscia Annonaria, appare evidente come, forse anche in virtù della scarsa incidenza numerica sul totale del campione di cui si è già parlato passim, le tipologie strutturali e funzionali, nell'ampio arco di tempo compreso tra il IV ed il VI secolo, risultino ampiamente eterogenee e scarsamente riconducibili ad una unica modalità programmatica. Un dato che spicca è sicuramente quello relativo alle preesistenze strutturali, dal momento che nessuno dei contesti da noi descritti risulta fondato ex novo in bacini topografici che non avessero già evidenze di frequentazione ed insediamento almeno dall'età imperiale, aspetto che si pone come uno dei più stimolanti, ma anche di più complessa comprensione e soluzione, in primis nell'ottica di una percezione delle modalità di fondazione dei singoli contesti, aspetto su cui, comunque, si tornerà più dettagliatamente nelle considerazioni conclusive.

Anche in ambito rurale, così come abbiamo visto nelle città, il VII e l'VIII secolo, pur con valori numerici leggermente differenti (si vedano i grafici a fig. 2), rivelano tendenze analoghe, ove il VII tradisce un 'vuoto' impressionante di fondazioni ecclesiastiche, che, in parte, potrebbe trovare spiegazioni affini a quelle proposte per gli ambiti urbani (vedi supra), cui si deve però aggiungere una generale riconfigurazione dei paesaggi, intesi lato sensu, comprendendo, dunque, anche le dinamiche insediative che, proprio nel VII secolo, sembrarono attraversare il proprio picco negativo. Il ben noto 'modello toscano' ${ }^{\prime 16}$, infatti, vide proprio nel VII il momento in cui le aristocrazie avrebbero avuto un ruolo molto debole nelle forme di gestione del territorio e delle risorse ${ }^{117}$, secondo circostanze in cui si sarebbe venuta

\footnotetext{
"12 G. CIAMPOLTRINI, I materiali. Un contributo per la definizione cronologica delle fasi della pieve, in G. Ciampoltrini, (a cura di), San Pietro in Campo a Montecarlo. Archeologia di una "plebs baptismalis" del territorio di Lucca, Lucca, 2007, p. 87-93.

${ }^{13}$ G. CIAMPOLTRINI, La città e la pieve. Paesaggi urbani e rurali di Lucca fra Tarda Antichità e Alto Medioevo, in G. Ciampoltrini (a cura di), op. cit. (n. 112), p. 15-67, in particolare a p. 37; si veda anche G. CIAMPOLTRINI 2008, Vie e pievi, pievi e castelli. Storie parallele di due plebes baptismales del territorio di Lucca, in S. Campana, C. Felici, R. Francovich, F. Gabbrielli (a cura di), op. cit. (n. 2), pp. 95-115.

${ }^{114}$ G. CIAMPOLTRINI, op. cit. (n. 113), pp. 104-106.

${ }^{15}$ Si vedano F. CANTINI, La chiesa e il borgo di San Genesio: Primi risultati dello scavo di una grande pieve della Toscana altomedievale (campagne scavo 2001-2007), in S. Campana, C. Felici, R. Francovich, F. Gabbrielli (a cura di), op. cit. (n. 2), p. 65-94; F. Cantini, F. Salvestrini (a cura di), Vico Wallari-San Genesio: ricerca storica e indagini archeologiche su una comunità del medio Valdarno inferiore fra alto e pieno Medioevo: giornata di studio, San Miniato, 1 dicembre 2007, Firenze, 2010.

${ }^{116}$ Il modello toscano, elaborato da Riccardo Francovich e Marco Valenti, ha i propri punti principali in "a) Decadenza del sistema delle ville e dell'organizzazione del popolamento rurale tra V e VI secolo con un'accentuazione progressiva della crisi b) Formazione del villaggio altomedievale intorno agli inizi del VII secolo, con il passaggio all'insediamento accentrato come forma di popolamento predominante c) Ruolo "debole" delle aristocrazie almeno sino alla metà del VII secolo che mostrano di assumere iniziative di maggior portata nell'organizzazione della campagna soprattutto dall'VIII secolo d) Trasformazione di molti villaggi in aziende che si realizza attraverso l'adattamento della curtis alle strutture del villaggio stesso nel corso del IX secolo e) Evoluzione dei villaggi in castelli al cui interno convivono nel X secolo sia la connotazione aziendale sia l'aspetto di dominio sul territorio" (da M. VALENTI, op. cit. (n. 15), p. 195).

${ }^{177}$ In tempi relativamente recenti, infatti, il quadro insediativo della Toscana post 500 d.C. è stato definito come un momento di "complete breakdown of all settlement hierarchies" (CH. WICKHAM, Framing the Early Middle Ages. Europe and the Mediterranean, 400-80o, Oxford, 2005, p. 485).
} 
a verificare una (conseguente?) forma di riorganizzazione delle forme del popolamento, in fase di progressivo accentramento $^{118}$ : il VII secolo, dunque, verrebbe a strutturarsi come vero e proprio 'momento di passaggio', ove, dunque, la scarsa autonomia di iniziativa da parte delle élites avrebbe parzialmente cristallizzato la possibilità di investire nella strutturazione di una fitta rete ecclesiastica - in fieri già, come abbiamo visto, in età tardo antica - che avrebbe avuto un rilancio impressionante solo a partire dall' VIII secolo.

Questa tendenza è innanzitutto leggibile molto chiaramente nel dato numerico ottenuto dalla schedatura - indice di un picco di nuove fondazioni - ma anche negli investimenti strutturali che vennero realizzati nelle strutture già esisten$\mathrm{ti}^{119}$ : abbiamo visto come questo fenomeno si verificò in parte anche nelle città, soprattutto in età carolingia, con i potenziamenti monumentali realizzati precipuamente nelle ecclesiae episcopales, ma altrettanto si poté apprezzare nei contesti rurali. A San Piero a Grado, in un momento inquadrabile all'incirca alla seconda metà dell'VIII secolo, il pavimento della basilica venne sopraelevato di ca. $40 \mathrm{~cm}$ e, soprattutto, vennero aggiunte due absidiole nelle parti terminali delle navatelle laterali ${ }^{120}$, determinando un parziale stravolgimento dell'icnografia che rimanda alle innovazioni planimetriche che abbiamo potuto apprezzare nella tarda età longobarda e nella piena epoca carolingia ${ }^{121}$ : non solo, a questa fase sembrerebbe da attribuire anche la messa in opera di una colonna isolata al centro dell'abside principale, ritenuta "primitiva memoria del culto petrino"122, aspetto che, di concerto con gli altri interventi strutturali, ben si sposerebbe con il grande flusso di pellegrini da cui fu interessato il santuario nel corso di tutto l'alto medioevo (vedi supra) (fig. 7).

Anche Sant'Ippolito d'Anniano, nell'VIII secolo, venne notevolmente ampliata, con l'aggiunta, a meridione, di un ambiente quadrangolare, destinato a battistero (ben testimoniato dal rinvenimento archeologico del fons) $)^{123}$, e con un generale allargamento dell'aula basilicale (fig. 8), configurando una fase che, con pochi dubbi, è da attribuire alla prima attestazione nelle fonti, del 787 , dell'ecclesia baptismalis Sancti Ipoliti sita loco Aniano, da cui doveva dipendere il vicino oraculum Sancte Marie in montem ${ }^{124}$. Anche a San Pietro in Campo si assistette ad un importante modifica dei corpi di fabbrica, con l'unificazione dei due ambienti giustapposti, che comportò una diretta comunicazione tra battistero ed aula basilicale vera e propria tramite una fila di pilastrii $^{125}$ (fig. 9). Tale impresa è stata attribuita ad un arco cronologico piuttosto ampio, compreso tra VIII e X secolo, e sarebbe da riconnettere, plausibilmente, come suggerito da Giulio Ciampoltrini ${ }^{126}$, a quella temperie di attività di diretta iniziativa vescovile che animarono la pieve nei pieni secoli altomedievali, in primis la serie di atti promossi il 12 di gennaio del 914 nella pieve stessa ${ }^{127}$, volti ad incentivare la costruzione del vicino castello di Petra Bovula, che posero San Pietro in Campo non solo al centro della cura animarum, ma anche in un ruolo di primo piano negli equilibri politico-economici.

A partire dalla fine del VII-inizi dell'VIII secolo, inoltre, si testimoniò anche l'eccezionale sviluppo del già citato contesto di vicus Wallari/San Genesio (San Miniato - Pi), in cui venne edificata una chiesa di grandi dimensioni (ca. $36 \times 17 \mathrm{~m}$ ), con tre absidi ${ }^{128}$ (si veda fig. 10), che diventò il luogo in cui, molto probabilmente, nel 715 fu risolta la ben nota contesa tra i vescovi di Arezzo e Siena per il possesso alcune pievi in territorio di confine tra le due diocesi ${ }^{129}$, exemplum, anche in questo caso, di come proprio con l'VIII secolo la promozione dell'edilizia ecclesiastica in ambito rurale sarebbe divenuta il segno non solo di una più definita strutturazione della cura d'anime, ma anche di una maggior attenzione allo sfruttamento dei contesti rurali dal punto di vista politico-economico che vide, a partire dall'età carolingia, il momento del proprio definitivo consolidamento. Dal IX secolo, le chiese rurali assunsero il ruolo di principale veicolo di riscossione delle decime, caratterizzando, di conseguenza, anche i paesaggi: l'afflato di nuove fondazioni nelle campagne, infatti, mal si spiegherebbe, secondo chi scrive, esclusivamente come un'ulteriore volontà di rafforzamento della rete di strutture legate alla cura animarum, che già ampiamente si erano diffuse in età longobarda, ma, piuttosto, come un apparato intimamente legato alla riscossione tributaria e all'autorappresentazione. Inoltre, proprio a cavallo tra VIII e IX secolo, si diffusero tipologie edilizie piuttosto canonizzate, come i contesti di San Giusto alla Caipira $^{130}$, San Martino in Ducentola ${ }^{131}$ o, ancora, la chiesa

\footnotetext{
${ }^{188}$ A margine si evidenzia come, perlomeno nel territorio lucchese, in un momento in la Tuscia Langobardorum è ormai già configurata, si attesti un considerevole numero di vici, i cui toponimi rivelano una chiara matrice alloctona: vico Alahis, vico Elingo, vico Schulcamo, vico Gulfari, vico Turingo e vico Gundualdi (si veda G. CIAMPOLTRINI, La città di San Frediano. Lucca fra VI e VII secolo: un itinerario archeologico, Pontedera, 2011, alle p. 19-20).

"19 Una tendenza analoga trova riscontro anche in un recente studio, che vede il picco di attestazioni nel terzo venticinquennio dell'VIII secolo d.C. (R. FARINELLI, Churches and Social Élites in Early Medieval Tuscany: a Quantitative-Statistical Approach to the Episcopal Archive of Lucca, in J.C. SÁNCHEZ-PARDO, M. G. SHAPLAND (a cura di), Churches and Social Power in Early Medieval Europe. Integrating Archaeological and Historical Approaches, Turnhout, 2015, p. 157-181).

${ }^{120}$ F. REDI 2009, op. cit. (n. 99), p. 93. Per la cronologia si vedano anche P. SANPAOLESI, op. cit. (n. 36), p. 69-71 e F. REDI 1986, op. cit. (n. 99), p. 224).

${ }^{121}$ Si rimanda ancora a M. LUCHTERHANDT, op. cit. (n. 81).

${ }^{122}$ F. REDI, op. cit. (n. 99), p. 95.

${ }^{123}$ G. Ciampoltrini, R. Manfredini (a cura di), op. cit. (n. 106), pp. 35-42.

${ }^{124}$ Su quest'ultimo si vedano F. REDI, op. cit. (n. 83), e F. REDI, op. cit. (n. 99).

${ }^{125}$ G. Ciampoltrini (a cura di), op. cit. (n. 112); G. CIAMPOLTRINI, op. cit. (n. 113).

${ }^{126}$ G. CIAMPOLTRINI, op. cit. (n. 113), p. 112.

${ }^{127} \mathrm{MD} / \mathrm{V}, 3, \mathrm{n} .1148$.

${ }^{128}$ F. CANTini 2008, op. cit. (n. 113); F. Cantini, F. Salvestrini (a cura di), op. cit. (n. 115).

${ }^{129}$ Sulla contesa si veda, ivi bibl., C. FELICI, La contesa fra i vescovi di Siena e Arezzo: il punto di vista dell'archeologo, in P. Favia, G. Volpe (a cura di), Atti del V Congresso Nazionale di Archeologia Medievale, Firenze, 2009, p. 433-443.

${ }^{130}$ Attestata dal 987 d.C. (MD V/3, n. 1619).

${ }^{131}$ Attestata dall'893 d.C. (MD V/3, n. 985).
} 


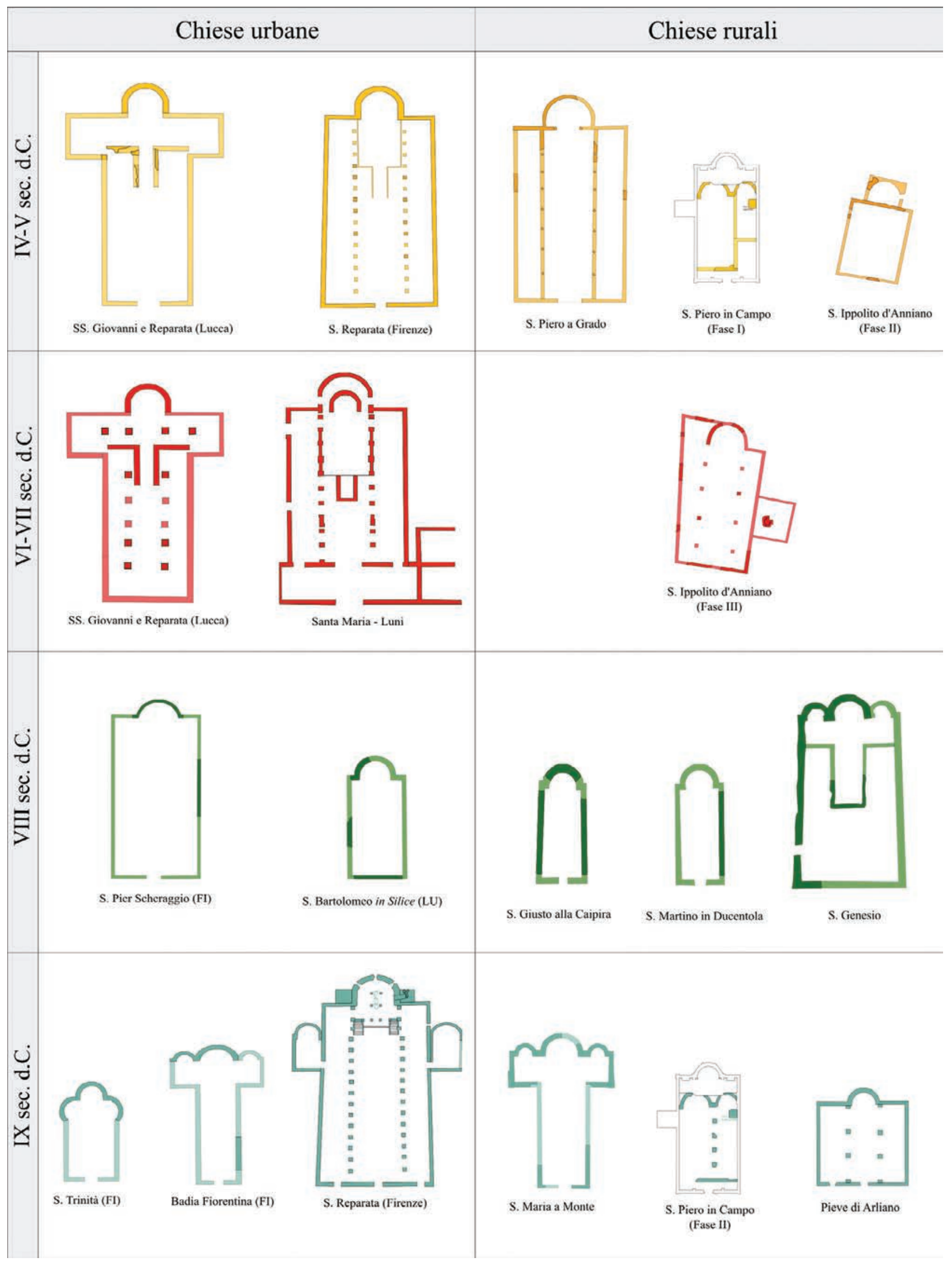

Fig. 10: Raffronti dimensionali-tipologici tra le principali chiese di ambito urbano e rurale (elaboraz. a.).

dei Ss. Martino e Giorgio a Pescia ${ }^{132}$, che si connotarono come semplici aule absidate, a navata unica, di dimensioni sostanzialmente analoghe tra loro (ca. 7 x $13 \mathrm{~m}$ ) (si veda la fig. 10): questi modelli icnografici risultano tutti pertinenti a chiese suffraganee, facenti capo alle pievi 'matrici', che erano ormai divenute i poli collettori delle decime, come bene attestano anche i documenti, su tutti un capitolare dell'813, in cui si esplicita come familiae vero ibi dent decimas

${ }_{132}$ Attestata dall'817 d.C. (MD IV/2, d. 13). 
suas ubi infantes eorum baptizantur, et ubi per totum anni circulum missas audiunt ${ }^{133}$.

\section{CONSIDERAZIONI CONCLUSIVE}

I dati sin qui concisamente descritti rappresentano, chiaramente, solo una sintesi di un insieme di informazioni ben più ampie, scaturite nel corso della schedatura di evidenze che tradiscono la presenza di istanze e tipologie a tratti eterogenee (fig. 10) ma, cionondimeno, consentono di delineare alcune tendenze e, allo stesso modo, si pongono, auspicabilmente, come spunti per eventuali ricerche future.

Nei contesti urbani, sul sottofondo di città che a partire dal III secolo si presentavano già in fase di profonda riconfigurazione, la comparsa dell'edilizia religiosa rappresentò uno degli aspetti più innovativi nel lungo percorso che portò alla formazione della civitas post classica. Nell'ambito del dibattito, però, non tutti gli studiosi sono concordi nell'attribuire alla strutturazione della topografia cristiana un ruolo fondamentale nei processi evolutivi della realtà tardo antica: Wolfgang Liebeschuetz, nel suo noto libro sul declino e la caduta della città romana, pur riconoscendo una parte importante al cristianesimo ed alle istituzioni ad esso legate, lo ritiene, però, un "indipendent factor", sostenendo che "Christian institutions, teachings, and ideals developed independently of imperial policy, and their evolution followed a logic of its own ${ }^{134}$ ", ponendo, de facto, la topografia cristiana (e tutto quanto ne conseguiva) come un fattore 'altro' rispetto alle dinamiche insediative, economiche ed istituzionali del mondo tardo romano, a differenza di Neil Christie che, alcuni anni dopo, afferma che "Alongside the politico- military power stood the church, whose buildings slowly filled the emerging architectural void. The relative unity of Christianity can be perceived as a new focus to a Roman society undergoing transformation ${ }^{135}$ ", secondo un'ottica che, invece, vede il cristianesimo come parte integrante di una società in trasformazione.

I dati che abbiamo qui proposto e, in generale, guardando al valore e all'impatto che ebbe la formazione della rete ecclesiastica urbana già dal tardo IV secolo (seppur, chiaramente, con tempi e modi differenti a seconda delle varie città) ${ }^{136}$ in buona parte del territorio italiano e non solo ${ }^{137}$, siamo autorizzati a ritenere che la topografia cristiana, con pochi dubbi, costituì forse l'elemento che più di tutti garantì la possibilità di rinnovamento - e, dunque, di persistenza topografica, seppur a discapito di una 'rottura' funzionale delle città nei secoli tardo antichi ed altomedievali ${ }^{138}$. In tale ottica, ovviamente, un punto di osservazione fondamentale è dato dal rapporto sia con le preesistenze, sia con il contesto insediativo contemporaneo all'inserimento degli edifici cristiani, nonché dalle modifiche sulla longue durée che questi ultimi apportarono all'organizzazione dei setti urbanistici: in tuti i casi da noi analizzati, le ecclesiae episcopales sorsero in ambito urbano, ma comunque in aree periferiche ${ }^{139}$ (fig. 11), e, fatto ancor più interessante, si andarono ad impostare sempre (sia a Luni, che a Firenze, che a Lucca che, probabilmente, anche a Pisa, vedi supra) in aree precedentemente occupate da domus e, dunque, in contesti privati. Non sempre, però, è chiarissimo il rapporto diretto tra domus ed ecclesia, ma, generalmente, sembrerebbe di assistere a casi in cui i contesti abitativi privati entrarono 'autonomamente' in fase di recessione e destrutturazione progressiva e che, solo successivamente, sui loro resti, talvolta obliterati da strati di livellamento, sarebbero stati edificati i complessi episcopali: è però chiaro che, in mancanza di fonti scritte od epigrafiche puntuali, non saremo forse mai in grado di capire completamente le dinamiche di passaggio di proprietà dei lotti urbani dai privati alla chiesa, ma rimane comunque un dato molto significativo che, nella zona qui studiata, il binomio di successione relativa "contesto privato-ecclesia episcopalis" sia una tendenza ben evidente e delineata, così come le chiese funerarie sembrino impostarsi (nei casi a noi noti archeologicamente) in aree già precedentemente occupate da necropoli (come la Santa Felicita fiorentina o il San Frediano lucchese), garantendo, in questo caso, una continuità non solo di ordine topografico, ma anche di destinazione funzionale.

La progressiva formazione della rete ecclesiastica urbana e suburbana, inoltre, determinò la genesi di nuovi equilibri insediativi, che avranno una straordinaria persistenza per tutto l'alto medioevo: è, ad esempio, il caso, ancora una volta, della fondazione della chiesa di San Frediano nel suburbium settentrionale di Lucca, che diede vita ad un vero e proprio nuovo polo insediativo, caratterizzato non solo da un edificio funerario-liturgico, ma anche da aree produttivo-artigianali e da nuclei residenziali, al punto che, nell'avanzato alto medioevo, quest'area vene definita come un vero e proprio borgo, con la denominazione burgo q.d. S. Fridiani ${ }^{140}$, analogamente a quanto avviene nelle zona di Santa Felicita a Firenze o, ancor di più, nell'area

\footnotetext{
${ }_{133}$ Monumenta Germaniae Historica, Concilia Aevi Karolini, p. 277 (ed. A. Werminghoff, Concilia Aevi Karolini, I, 1, Hannover-Lipsia, 19o6).

134 W. LIEBESCHUETZ, The Decline and Fall of the Roman City, Oxford, 2001, p. 412.

${ }^{135}$ N. CHRISTIE, From Costantine to Charlemagne. An Archaeology of Italy (AD 300-80o), Aldershot, 2006.

${ }^{136}$ Ancora attuale rimane P. TESTINI, G. CANTINO WATAGHIN, L. PANI ERMINI, La cattedrale in Italia, in Actes du XIe congrès international d'archéologie chrétienne (Lyon, Vienne, Grenoble, Genève, Aoste, 21-28 septembre 1986), Città del Vaticano, 1989, p. 5-229.

${ }^{137}$ G. CANTINO WATAGHIN, J. M. GURT ESPARRAGUERA, J. GUYON, Topografia della Civitas Christiana tra IV e VI sec., in G. P. Brogiolo (a cura di), Early Medieval Towns in the Western Mediterranean (Ravello, 22-24 September 1994), Mantova, 1996, p. 17-41; si vedano anche N. GAUTHIER, op. cit. (n. 26); N. GAUTHIER (avec la collaboration de B. Beaujard, J. Guyon, F. Prévot, G. Cantino Wataghin), Christianisation et espace urbain, in F. Prévot, M. Gaillard, N. Gauthier (a cura di), Topographie chrétienne des cités de la Gaule des origines au milieu du VIII siècle, XVI, 1-2, Paris, 2014, p. 359-399; PH. PERGOLA, Dalla civitas classica alla città sede di diocesi cristiana: teorie e metodi della topografia cristiana, in V. Ruggieri, L. Pieralli (a cura di) Eykosmia. Studi miscellanei per il $75^{\circ}$ di Vincenzo Poggi S. J., Roma, 2003, p. 341-375; PERGOLA, op. cit. (n. 26).

${ }_{138}$ Recentemente, Gian Pietro Brogiolo, a tal proposito, ha affermato che "In generale possiamo dire che i luoghi di culto, favorendo la persistenza dei tracciati stradali e degli impianti urbani, ne hanno promosso anche la continuità urbanistica" (G.P. BROGIOLO, op. cit. (n. 6o), p. 109) e che "non resta che ribadire che le fortificazioni e le chiese [...] sono gli elementi caratterizzanti della città altomedievale" (Ibidem, p. 123.).

${ }^{139}$ L'edificazione dei complessi episcopali in zone periferiche delle città è, del resto, tratto trasversale e caratterizzante delle realtà urbane tardo antiche di quasi tutto il territorio italiano, si veda a tal proposito P. TESTINI, G. CANTINO WATAGHIN, L. PANI ERMINI, op. cit. (n. 136).

${ }^{14^{\circ}}$ Attestazione del 998 d.C. (RCL, I, op. cit., nn. 183-184).
} 


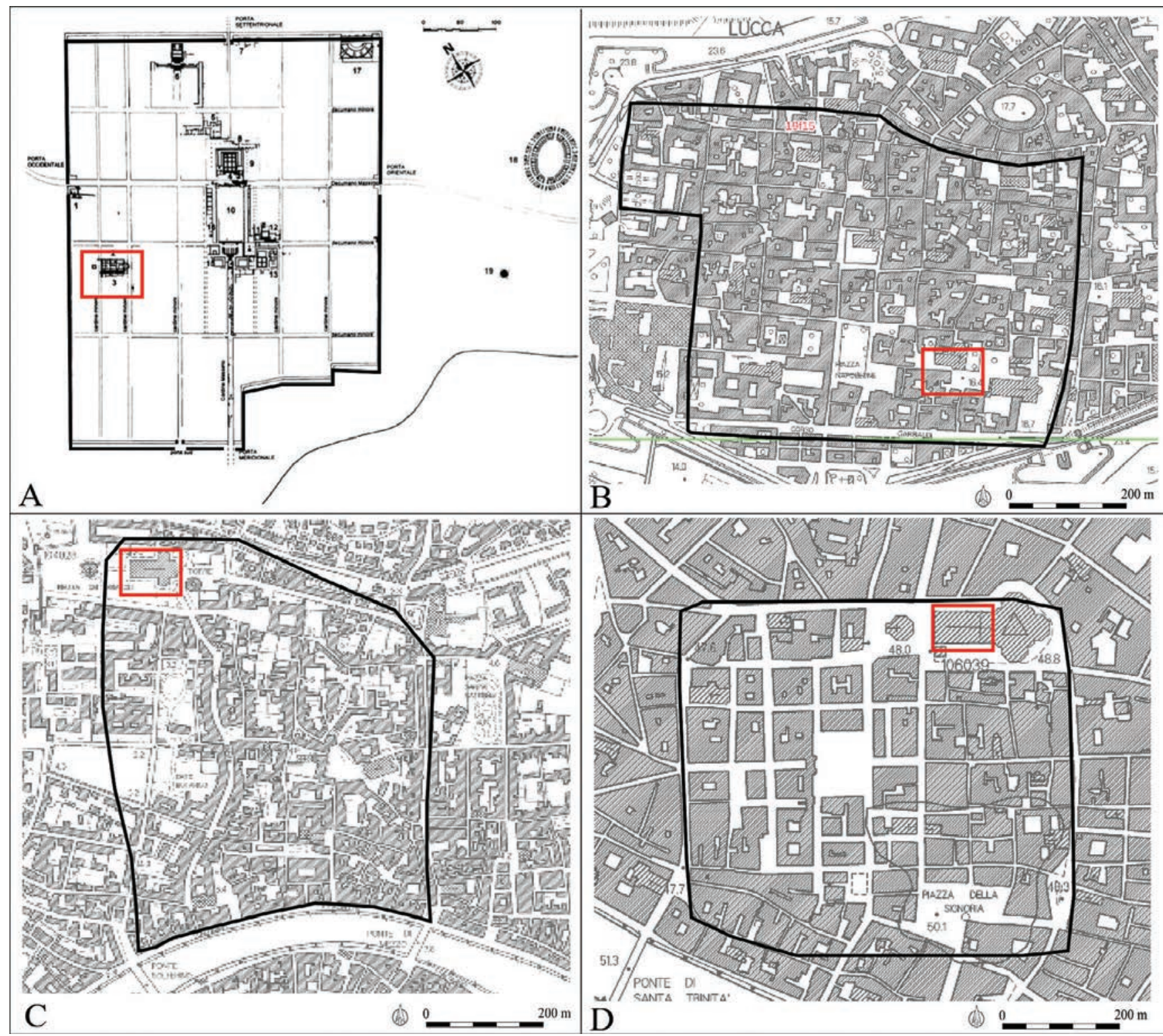

Fig. 11: Nei riquadri rossi le collocazioni topografiche delle ecclesiae episcopales, in relazione ai tracciati murari di epoca romana A) Luni B) Lucca C) Pisa (l'andamento delle mura è in gran parte ipotetico), D) Firenze (elaboraz. a.)

sud-orientale del profilo urbano lucchese, ove la convivenza tra episcopium, curtis regia e zecca connotò il quartiere di riferimento della città altomedievale, una sorta di 'città nella città', in cui si articolarono le diverse anime: gli edifici cristiani in città e nei suburbia, dunque, non sono solo un epifenomeno, ma piuttosto, un vero e proprio "fattore poleogenetico"141.

Un ulteriore aspetto su cui soffermarsi brevemente è quello legato al rapporto tra spazi urbani, edifici ecclesiastici e sepolture: a livello generale, i dati a disposizione per le città toscane sembrerebbero indicare una tendenza (peraltro ben nota e comune a quasi tutte le realtà urbane del Mediterraneo) ${ }^{142}$ per cui la diffusione delle inumazioni intra muros sia in età tardo antica, fino almeno al VI secolo compreso, un fenomeno episodico e legato, comunque, a contingenze occasionali, piuttosto che ad una vera e propria programmaticità. Non solo, in ogni caso, le chiese suburbane sembrerebbero continuare ad essere i vettori principali delle pratiche funerarie per tutto l'alto medioevo, un ipotesi che è possibile avanzare soprattutto in base ad osservazioni indirette: se a partire dall'avanzato VI e soprattutto dal VII secolo anche le chiese intramuranee iniziarono ad essere interessate dall'inserimento di aree cimiteriali, è pur vero che, comunque, non si trattò di grandi cimiteri ben organizzati ma, anzi, piuttosto, di spazi di inumazione circoscritti a pochi individui, come è ben documentabile nelle ecclesiae

${ }^{141}$ L. PANI ERMINI, La "città di pietra": forma, spazi e strutture, in Morfologie sociali e culturali in Europa fra tarda antichità e alto Medioevo, XLV Settimana CISAM, Spoleto, 1998, p. 211-255. A margine di tale considerazione, si sottolinea come l'incidenza della fitta rete ecclesiastica, soprattutto a Lucca, sembri imporre una parziale ridiscussione del modello di "città ad isole" (si veda su tale aspetto G. CASTIGLIA, op.cit. (n. 16); già Chris Wickham, nel 2005, affermava, infatti: "I have serious doubts about this, all the same, given the even density of the city's numerous intramural churches in the eighth century": $\mathrm{CH}$. WICKHAM, op. cit. (n. 117), p. 653), avanzato da numerosi studiosi (si veda ad esempio G. CIAMPOLTRINI, Città "frammentate" e città fortezza. Storie urbane della Toscana centro-settentrionale fra Teodosio e Carlo Magno, in R. Francovich, G. Noyé (a cura di), La storia dell'alto medioevo italiano (VI-X secolo) alla luce dell'archeologia, Firenze, 1994, p. 615-633).

${ }^{142} \mathrm{~V}$. FIOCCHI NICOLAI, Elementi di trasformazione dello spazio funerario tra tarda antichità ed altomedioevo, in Uomo e spazio nell'alto medioevo, L Settimana di studi CISAM (Spoleto, 4-8 aprile 2002), Spoleto, 2003, p. 921-970. 


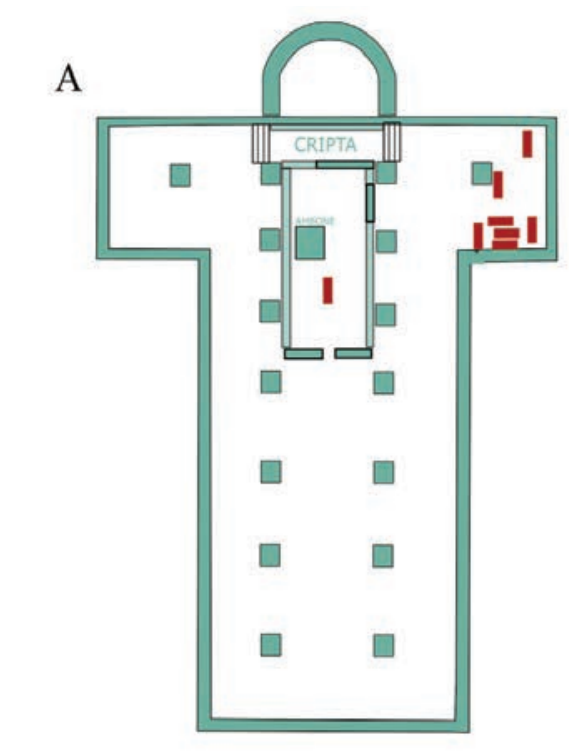

$=$ sepolture altomedievali

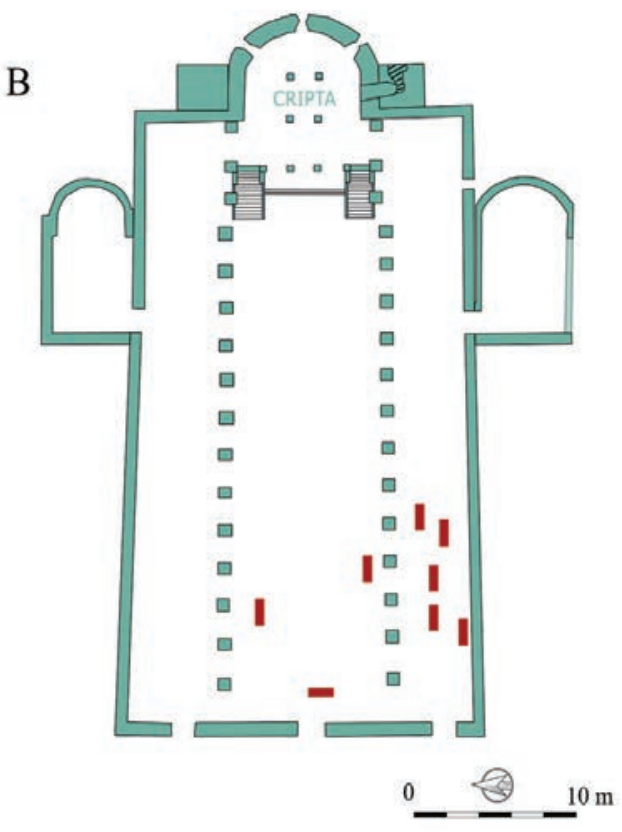

Fig. 12: In rosso le sepolture di epoca altomedievale in relazione alle ecclesiae episcopales A) Lucca B) Firenze (elaboraz. a.).

episcopales di Firenze ${ }^{143}$ e Lucca ${ }^{144}$ (fig. 12): questa tendenza è stata recentemente ben messa in evidenza anche per l'Italia settentrionale ${ }^{145}$ ove "l'uso delle chiese cattedrali come spazio funerario è un fenomeno tardo che si avvia a partire dal VII secolo e si diffonde soprattutto dall'VIII-IX secolo ${ }^{146 ", ~ s i n t o-~}$ mo ben evidente anche nel nostro territorio, in cui peraltro si viene a verificare un continuum nella predilezione da parte degli stessi vescovi a farsi inumare nei contesti suburbani, come nel San Frediano Lucchese, ove ancora nel IX secolo trovavano riposo gli episcopi $i^{147}$.

Di più complessa lettura è invece la formazione del sistema di edifici ecclesiastici negli ambiti rurali, in particolar modo nelle sue fasi incipitarie, financo almeno all'avanzato VII secolo. Ripartendo dal modello destrutturante di Cinzio Violante citato nelle battute iniziali di questo contributo, il panorama che scaturisce dai dati schedati e qui presentati sembrerebbe discostarsi parzialmente dalla lectio avanzata dal grande storico. Durate i secoli tardo antichi, come abbiamo visto, la Tuscia Annonaria rurale sembrò, a differenza della Suburbicaria, garantire una maggior tenuta degli assetti insediativi - con anche importanti interventi in alcuni complessi (vedi supra) - ed economici (si registrano siti produttivi attivi fino ad almeno il VI secolo ${ }^{148} \mathrm{e}$ la penetrazione di merci di importazione anche in contesti dell'entroterra, seppur ormai in numero ridotto rispetto ai secoli precedenti $\left.{ }^{149}\right)$ : in che modo, dunque, si incardinò il cristianesimo nelle proprie istanze materiali? Le fondazioni ecclesiastiche furono "scarse, insicure" ${ }^{150}$, oppure, dietro questo velo di Maya, è possibile intravvedere una realtà differente?

Indubbiamente, soffermandosi ad un'analisi limitata esclusivamente al dato quantitativo, il paradigma proposto da Cinzio Violante sembrerebbe avere una ricaduta anche dal punto di vista materiale, ma i seppur scarsi casi di chiese di età tardo antica a noi noti archeologicamente ci obbligano ad un ulteriore sforzo interpretativo: innanzitutto, i contesti che abbiamo descritto mettono chiaramente in evidenza il fatto che i siti attestati nelle fonti per la prima volta solamente a partire nell'arco temporale compreso tra $\mathrm{i}$ secoli VIII-X in realtà, una volta indagati stratigraficamente, abbiano restituito significative fasi ben più antiche della prima menzione nei documenti, attribuibili perlomeno ai decenni introduttivi del V secolo, per cui nulla esclude di ritenere che, a fronte di progetti sistematici di ricognizione e scavo dei numerosissimi altri contesti che godono di attestazioni nelle fonti altomedievali, non si possano trovare ulteriori conferme di complessi ecclesiastici più antichi. Non solo, i dati a noi noti rivelano un panorama eterogeneo e, comunque, spia di una configurazione della rete ecclesiastica rurale che, inevitabilmente, doveva essere già in fieri anche

\footnotetext{
${ }_{143}$ F. TOKER 2013, op. cit. (n. 33), p. 163; B. RIDI, E. PARDINI. D. DIRKMAAT, Skeletal remains at S. Reparata, in F. Toker 2013, op. cit. (n. 33 ), p. $455-466$. ${ }^{144}$ L. PANI ERMINI, op. cit. (n. 30); M.G. FICHERA, M.L. MANCINELLI, F.R. STASOLLA, Le sepolture altomedievali, in G. Piancastelli Politi Nencini (a cura di), op. cit. (n. 29), p. 197-200.

${ }^{145}$ A. CHAVARRÍA ARNAU, F. GIACOMELLO, Riflessioni sul rapporto tra sepolture e cattedrali nell'alto medioevo, in Hortus Artium Medievalium, 20 , 2014, pp. 209-220; A. CHAVARRÍA ARNAU, F. GIACOMELLO, Sepolture e cattedrali in Italia settentrionale: il dato archeologico, in Rivista di Archeologia Cristiana, 91, 2015, p. 129-166.

${ }^{146}$ A. CHAVARRÍA ARNAU, F. GIACOMELLO, op. cit. (n. 145), p. 216.

147 Si veda, passim, I. BELLI BARSALI, La topografia di Lucca nei secoli VIII-XI, in Lucca e la Tuscia nell'Altomedieovo. Atti del V Congresso Internazionale di Studi sull'Alto Medioevo, Spoleto 1973, p. 461-554.

${ }^{148}$ F. CANTINI, op. cit. (n. 89).

149 F. CANTINI, Produzioni ceramiche e dinamiche commerciali nel territorio toscano (III-metà VIII secolo): l'area interna, in E. Cirelli, F. Diosono, H. Patterson (a cura di), Le forme della crisi. Produzioni ceramiche e commerci nell'Italia centrale tra Romani e Longobardi (III-VIII secolo d.C.), Bologna, 2015, p. 183-19o (si veda in particolare pp. 187-188).

${ }^{150}$ C. VIOLANTE, op. cit. (n. 9), p. 990.
} 
nelle campagne, altrimenti mal si spiegherebbe la presenza di un contesto come San Pietro in Campo, che già agli inizi del V garantiva la cura animarum ${ }^{151} \mathrm{o}$, ancor di più, di un sito dalle proporzioni grandiose e monumentali come San Piero a Grado.

Evidentemente, però, il dato quantitativo, per quanto plausibilmente 'soffocato' dai limiti più volte esposti, deve essere parimenti considerato e, pertanto, è forse possibile avanzare una mediazione tra lo 'spessore dei numeri' ed il valore 'qualitativo' dei dati a nostra disposizione: se, indubbiamente, non è ancora pensabile tratteggiare chiaramente, nelle campagne tardo antiche della Tuscia Annonaria, la presenza di una rete ecclesiale paragonabile a quella che si configurò a partire dal secolo VIII, risulta comunque plausibile ipotizzare la presenza di comunità cristiane rurali, anche piuttosto consistenti, che necessitassero, già in tale ambito cronologico, di chiese che potessero assolvere alle funzioni battesimali e, più semplicemente, della liturgia ebdomadaria, come in nuce sembrano rivelare i siti presentati. Allo stato attuale delle conoscenze, dunque, i 'paesaggi cristiani' della Tuscia, dal V al VI-VII secolo, sembrerebbero assumere contorni più fluidi e complessi rispetto all'univocità proposta da Cinzio Violante, considerazione che è stata recentemente avanzata anche per contesti più ampi, sostenendo che "l'età tardoantica appare sempre meno riconducibile a dinamiche lineari, quali ancora erano suggerite nel 1982 dallo studio di Cinzio Violante, che pure è stato fondamentale e ancora oggi, a distanza di oltre trent'anni, costituisce un riferimento ineludibile" ${ }^{152}$. In relazione a questi aspetti, analogamente a quanto abbiamo tentato di fare per le città, è opportuna una riflessione inerente $\mathrm{i}$ rapporti con le preesistenze: in tutti i casi analizzati, gli edifici ecclesiastici di epoca tardo antica sorsero su bacini topografici già frequentati in precedenza secondo forme insediative più o meno eterogenee, ma risulta estremamente complesso comprendere il reale rapporto tra tali bacini e le chiese. In particolar modo, la mancanza di indagini in open area rende sfuggente soprattutto la com- prensione delle relazioni tra gli edifici ecclesiastici egli insediamenti ad essi precedenti nella loro globalità ma, in base a quanto è possibile verificare, sembrerebbe che, perlomeno nei punti in cui le chiese furono edificate, le strutture più antiche siano state o riadattate (come a San Piero a Grado) o, addirittura obliterate (dunque, abbandonate). Ne consegue che, pertanto, risulta estremamente complesso comprendere sino in fondo se si trattò di chiese che sorsero all'interno di insediamenti in parziale stato di recessione o meno, quantunque risulti molto difficile ritenere che, qualsiasi interpretazione si possa dare a questo fenomeno, l'edificazione di queste chiese rurali possa essere sorta esclusivamente per diretta iniziativa di privati, senza un significativo e decisivo ruolo da parte dei vescovi ${ }^{153}$.

In un ambito socio-topografico che, come abbiamo visto, vede nelle città un ruolo 'forte' della topografia cristiana (e, dunque, della presenza degli episcopi) e, di contro, un panorama più ondivago nelle campagne, è proprio all'iniziativa dei vescovi che dobbiamo guardare come vettore principe dell'impulso alla formazione di una rete di chiese volte sia alla cura animarum che alla promozione di culti; bisogna però anche fare attenzione a rimarcare come un aspetto non escluda l'altro, dal momento che la grandiosità di determinati cantieri (San Piero a Grado, appunto) potrebbe essere comunque stata finanziata da ricchi possessores privati, previa autorizzazione del vescovo, in un mutuo rapporto, come già sottolineato da Vincenzo Fiocchi Nicolai che, pur evidenziando le numerose attestazioni nelle fonti di evergeti aristocratici che garantirono l'edificazione di chiese, sottolinea anche che "le chiese locali [...] mettevano a profitto le possibilità economiche dei ricchi possidenti per dotare le campagne di strutture idonee allo svolgimento della pastorale"154. Questo tipo di rapporto sembrò inoltre gradualmente intensificarsi nel corso dell'alto medioevo, seppur in forme inevitabilmente diversificate: il ruolo dei vescovi come fondatori e promotori risulta legato a doppia mandata a quello dei privati ed a quello dei rappresentanti del potere temporale ${ }^{155}$ : il continuum di

${ }^{151}$ Il momento di passaggio tra la fine del IV e gli inizi del V sembra costituire, nel territorio italiano, proprio il momento di transizione da una fase - la fine del IV secolo - in cui l'amministrazione del battesimo in ambito rurale aveva ancora "un carattere di eccezionalità", ad un'altra - gli inizi del V - ove, ormai, "la prassi di battezzare nelle chiese di campagna si fosse ormai affermata" (V. FIOCCHI NICOLAI, S. GELICHI, Battisteri e chiese rurali (IV-VII secolo), in L'edificio battesimale in Italia. Aspetti e problemi (Atti dell'VIII congresso nazionale di archeologia cristiana: Genova, Sarzana, Albenga, Finale Ligure, Ventimiglia, 21-26 settembre 1998), Bordighera, 2001, p. 303-384, in particolare a p. 305-306).

${ }^{152}$ G. CANTINO WATAGHIN, op. cit. (n. 7), p. 192; su questi aspetti si veda anche G. CANTINO WATAGHIN, Christianisation et organisation ecclésiastique des campagnes: l'Italie du Nord aux IVe-VIIIe siècles, in G.P. Brogiolo, N. Gauthier, N. Christie (a cura di), Towns and their territories between Late Antiquity and the Early Middle Ages, Leiden, 2000, p. 209-234.

${ }^{153}$ A sostegno di questa ipotesi si rimanda a A. CHAVARRÍA ARNAU, Chiese ed oratori domestici nelle campagne tardoantiche, in F. Ghedini, M. Bassani (a cura di), Religionem significare. Aspetti storico-religiosi, strutturali, iconografici e materiali dei Sacra Privata, Atti dell'Incontro di Studi (Padova, 8-9 giugno 2009), Roma, 2011, p. 229-243; si vedano anche EAD., Archeologia delle chiese. Dalle origini all'anno Mille, Roma, 2009, in particolare alle p. 155-169 e EAD., Changes in scale in the Italian countryside from Late Antiquity to the Early Middle Ages, in J. Escalona, A. Reynolds (a cura di), Scale and Scale Change in the Early Middle Ages. Exploring Landscape, Local Society and the World Beyond, Turnhout, 2010, p. 121-132.

${ }^{154} \mathrm{~V}$. FIOCCHI NICOLAI, Il ruolo dell'evergetismo aristocratico nella costruzione degli edifici di culto cristiani nell'hinterland di Roma, in G.P. Brogiolo, A. Chavarría Arnau (a cura di), Archeologia e società tra tardo antico e alto medioevo, Mantova, 2007, p. 107-126: p. 117. Kimberly Bowes, invece, vede un ruolo pressoché esclusivo dei privati nella fondazione delle chiese rurali, fino almeno al VI secolo d.C., ritenendo che "Indeed, archaeological evidence from the Western provinces suggests that in many areas, it was the estate, not the episcopate, which sponsored the first Christian buildings in the countryside" (K. BOWES, "Christianization" and the Rural Home, in Journal of Early Christian Studies, 15, 2007, p. 143-17o; p. 156; si veda anche K. BOWES, Private Worship, Public Values and Religious Change in Late Antiquity, New York, 2008, in particolare p. 125-188). In generale, per una sintesi bibliografica sul dibattito si rimanda a A. CHAVARRÍA ARNAU, T. LEWIT, Archaeological research on the late antique countryside: a bibliographic essay, in W. Bowden, L. Lavan, C. Machado (a cura di), Recent Research on the Late Antique Countryside, Leiden, 2004, p. 3-51, in particolare p. 38-43 e al più recente C. SFAMENI, Residenze e culti in età tardo antica, Roma, 2014.

${ }^{155}$ Un rapporto tra stato e chiesa caratterizzato da una reciproca interdipendenza era stato messo in evidenza anche da Chris Wickham nel 1986, quando lo studioso affermava che "it is the church standing in for the state, rather than the church exercising private judicial powers over its own properties" (CH. WICKHAM, Land Disputes and their Social Framework in Lombard-Carolingian Italy, 70o-90o, in H. Mayr-Harting, R.I. Moore (a cura di), Studies in Medieval History Presented to R.H.C. Davis, London, 1985, p. 53-71, in particolare a p. 53). Inoltre, gli importanti lavori di Anne Mailloux, hanno bene 
fondazioni di chiese in ambito rurale per tutto il IX secolo (a differenza del picco negativo documentato per le città in questo stesso torno cronologico) è spia di nuove politiche di investimenti economici e di gestione del territorio, con la progressiva strutturazione del sistema curtense e della rete delle plebes ${ }^{156}$, perni - come abbiamo già sottolineato - della riscossione delle decime.

Il ruolo della chiesa, dunque, a partire dall'avanzato IV-inizi del $\mathrm{V}$ secolo, assume sia un valore di primo pia- no nelle dinamiche di evoluzione topografica urbana sia nella ridefinizione dei paesaggi rurali, un ruolo in crescita esponenziale, che vede nell'VIII e nel IX il proprio zenit e si afferma come uno degli elementi principi nella declinazione della longue durée dell'alto medioevo della Tuscia. L'elefante, dunque, continua a sedere nel salotto: ma non è più ospite ingombrante ed indesiderato, ma ormai anfitrione generoso e loquace.

evidenziato come dall'VIII-IX secolo d.C. i vescovi lucchessi fossero costantemente legati alle più eminenti famiglie aristocratiche e che la formazione dei notai (evidentemente una delle cariche 'laiche' più importanti) fosse di esclusiva pertinenza delle élites (A. MAILLOUX, Modalités de constitution du patrimoine épiscopal de Lucques, VIII ${ }^{e}$-X siecle, in MEFRM, Moyen Âge, Temps modernes, 111-2, 1999, p. 701-723), in un sorta di ineludibile mutuo legame tra la sfera temporale e spirituale, ormai coese nella gestione politico-economica di città e contado.

${ }^{156}$ In generale, sui processi di formazione del sistema 'parrocchiale', in vari ambiti geografici, si rimanda a Ph. Pergola (a cura di), Alle origini della parrocchia rurale (IV-VIII sec.). Atti della giornata tematica dei Seminari di Archeologia Cristiana, (École française de Rome - 19 marzo 1998), Città del Vaticano, 1999 e Ch. Delaplace (a cura di), Aux origines de la paroisse rurale en Gaule méridionale, IV-Xe siècles, Colloque international (Toulouse, 21-23 mars 2003), Paris, 2005. 